\title{
Long-term (1999-2019) variability of stratospheric aerosol over Mauna Loa, Hawaii, as seen by two co-located lidars and satellite measurements
}

\author{
Fernando Chouza $^{1}$, Thierry Leblanc ${ }^{1}$, John Barnes ${ }^{2}$, Mark Brewer ${ }^{1}$, Patrick Wang ${ }^{1}$, and Darryl Koon ${ }^{1}$ \\ ${ }^{1}$ Jet Propulsion Laboratory, California Institute of Technology, Wrightwood, CA, USA \\ ${ }^{2}$ NOAA/ESRL/Global Monitoring Division, Boulder, CO, USA \\ Correspondence: Fernando Chouza (keil@jpl.nasa.gov)
}

Received: 26 November 2019 - Discussion started: 14 January 2020

Revised: 4 May 2020 - Accepted: 12 May 2020 - Published: 10 June 2020

\begin{abstract}
As part of the Network for the Detection of Atmospheric Composition Change (NDACC), ground-based measurements obtained from the Jet Propulsion Laboratory (JPL) stratospheric ozone lidar and the NOAA stratospheric aerosol lidar at Mauna Loa, Hawaii, over the past 2 decades were used to investigate the impact of volcanic eruptions and pyrocumulonimbus (PyroCb) smoke plumes on the stratospheric aerosol load above Hawaii since 1999. Measurements at 355 and $532 \mathrm{~nm}$ conducted by these two lidars revealed a color ratio of 0.5 for background aerosols and small volcanic plumes and 0.8 for a PyroCb plume recorded on September 2017. Measurements of the Nabro plume by the JPL lidar in 2011-2012 showed a lidar ratio of $(64 \pm 12.7) \mathrm{sr}$ at $355 \mathrm{~nm}$ around the center of the plume. The new Global Space-based Stratospheric Aerosol Climatology (GloSSAC), Cloud-Aerosol Lidar with Orthogonal Polarization (CALIOP) Level 3 and Stratospheric Aerosol and Gas Experiment III on the International Space Station (SAGE III-ISS) stratospheric aerosol datasets were compared to the ground-based lidar datasets. The intercomparison revealed a generally good agreement, with vertical profiles of extinction coefficient within $50 \%$ discrepancy between 17 and $23 \mathrm{~km}$ above sea level (a.s.l.) and $25 \%$ above $23 \mathrm{~km}$ a.s.l. The stratospheric aerosol depth derived from all of these datasets shows good agreement, with the largest discrepancy $(20 \%)$ being observed between the new CALIOP Level 3 and the other datasets. All datasets consistently reveal a relatively quiescent period between 1999 and 2006, followed by an active period of multiple eruptions (e.g., Nabro) until early 2012. Another quiescent period, with slightly higher aerosol background, lasted until mid-2017, when a combination of exten-
\end{abstract}

sive wildfires and multiple volcanic eruptions caused a significant increase in stratospheric aerosol loading. This loading maximized at the very end of the time period considered (fall 2019) as a result of the Raikoke eruption, the plume of which ascended to $26 \mathrm{~km}$ altitude in less than 3 months.

\section{Introduction}

The impact of stratospheric aerosols in the Earth's radiative budget and ozone burden is widely recognized (e.g., Thompson and Solomon, 2009; Hofmann and Solomon, 1989). Their characterization is not only important to understand the changes in atmospheric temperature and ozone profiles but has also gained relevance during recent years because of their potential use as a geoengineering tool to reduce the impact of global warming (Rasch et al., 2008). Dominated by sulfate aerosols, stratospheric aerosols are typically found in the form of a layer that extends from the tropopause up to $35 \mathrm{~km}$ above sea level (a.s.l.) in the tropics and about $30 \mathrm{~km}$ a.s.l. at midlatitudes (Hitchman et al., 1994; Kremser et al., 2016). This stratospheric aerosol layer (SAL), also known as Junge layer, was discovered in 1960 by means of balloon-borne measurements (Junge and Manson, 1961).

Although the stratospheric sulfur burden has been dominated by periodic volcanic injections of large amounts of $\mathrm{SO}_{2}$ and volcanic ash (Kremser et al., 2016) during past decades, some recent studies (Solomon et al., 2011) reported an increase in the background aerosol load during less active volcanic periods that could be attributed to other sources, including anthropogenic $\mathrm{SO}_{2}$ emissions (Brock et al., 1995; Rollins 
et al., 2018) and large wildfire-driven thunderstorms (Peterson et al., 2018).

Since its discovery, several techniques have been used to monitor the evolution of the SAL, including groundbased lidars (e.g., Fiocco and Grams, 1964; Barnes and Hofmann, 2001; Trickl et al., 2013; Khaykin et al., 2017; Zuev et al., 2017), balloon-borne in situ measurements (Deshler et al., 2003), and satellite-borne lidars (Vernier et al., 2009) and spectrometers (McCormick and Veiga, 1992). While satellite-borne instruments are able to provide global coverage over several years, their limited lifetime requires additional measurements that can close eventual gaps existing between different missions, but they can provide a common reference to investigate possible instrumental biases that can arise from the difference in the measurement techniques and wavelengths used on each mission.

As part of the Network for the Detection of Atmospheric Composition Change (NDACC), the Jet Propulsion Laboratory (JPL) lidar group has been performing stratospheric ozone and temperature measurements at Mauna Loa, Hawaii, since 1994 (e.g., Leblanc et al., 2006; Kirgis et al., 2013). This long-term ground-based lidar dataset provides not only stratospheric ozone and temperature records but also a unique opportunity to evaluate current and past global stratospheric aerosol datasets. In contrast to most stratospheric aerosol systems, the JPL stratospheric ozone lidar operates in the ultraviolet spectral region $(308-387 \mathrm{~nm})$ and has two different Raman receivers that allow the retrieval of aerosol extinction coefficient $\left(\alpha_{\mathrm{a}}\right)$ profiles without the need to assume a lidar ratio.

Additionally, right next to the JPL ozone lidar, the National Oceanic and Atmospheric Administration (NOAA) has been collecting stratospheric aerosol measurements with a ruby-based lidar system $(694 \mathrm{~nm})$ since the mid-1970s and with an Nd:YAG laser (532 nm) since May 1994.

In this study, the JPL and NOAA lidars are used to investigate the stratospheric aerosol optical properties in the UV and visible spectral regions and to evaluate three different extinction profile datasets, i.e., the multi-instrument Global Space-based Stratospheric Aerosol Climatology (GloSSAC, Thomason et al., 2018), the new Cloud-Aerosol Lidar with Orthogonal Polarization (CALIOP) Level 3 Stratospheric Aerosol Profile Monthly Product (Kar et al., 2019), and the recently launched Stratospheric Aerosol and Gas Experiment III on the International Space Station (SAGE III-ISS) (Cisewski et al., 2014).

The paper is organized as follows. Section 2 provides a brief description of the instruments and datasets used in this study, including a description of the JPL and NOAA lidars and the three satellite-based datasets. Section 3 describes the methods applied to the ground-based lidar datasets in order to retrieve aerosol backscatter and extinction profiles as well as aerosol optical depth and the corrections needed in order to obtain comparable datasets. Section 4 provides an overview of the measurements conducted at Mauna Loa in the period between 1999 and 2019 and the different optical properties retrieved from the synergy between JPL and NOAA lidars. Section 5 presents lidar-derived optical properties. Section 6 presents an intercomparison of the two ground-based lidars with the three satellite-based datasets under evaluation. Finally, a summary of the key findings of this paper is presented in Sect. 7.

\section{Instruments and datasets}

\subsection{JPL Mauna Loa Stratospheric Ozone Lidar (MLSOL)}

The JPL Mauna Loa Stratospheric Ozone Lidar (MLSOL) started its routine operations in 1993. The system is deployed at the Mauna Loa Observatory, Hawaii $\left(19.53^{\circ} \mathrm{N}\right.$; $155.57^{\circ} \mathrm{W}, 3397 \mathrm{~m}$ a.s.l.). An extensive description of the original system configuration can be found in McDermid et al. (1995). Since then, the system has undergone a few major modifications and some minor technical issues. The major modifications include the migration of the system from a mobile trailer to a building, the replacement of the Raman shifting cell used to generate the $353 \mathrm{~nm}$ with a Nd:YAG laser in March 2001, and the upgrade on the data acquisition system in April 2019.

In its current configuration, the system transmitter consists of a Spectra Physics PIV-400 Nd:YAG laser operating at a repetition rate of $50 \mathrm{~Hz}$, followed by a third harmonic generator (THG), emitting pulses of about $140 \mathrm{~mJ}$ at $355 \mathrm{~nm}$. For the generation of the "on wavelength" needed for the ozone differential absorption lidar (ozone DIAL) retrieval, a set of two $\mathrm{XeCl}$ Excimer lasers is used. The first Excimer laser (Coherent LPXpro 220) is used as an oscillator, while the second is used as a single-pass amplifier (Lambda Physik LPX 220i). This configuration is operated at a repetition rate of $200 \mathrm{~Hz}$ with a pulse energy of about $300 \mathrm{~mJ}$ at $308 \mathrm{~nm}$. Both laser beams are expanded by a factor of 5 in order to reduce beam divergence and redirected to the atmosphere by motor-controlled mirrors used for alignment purposes.

The system receiver, mainly unchanged since the system description presented in McDermid et al. (1995), consists of a $1 \mathrm{~m}$ aperture Dall-Kirkham telescope with a focal ratio of $f / 8$. A PARC Model 192 chopper is placed between the telescope and the receiver in order to block backscatter signal from altitudes below $10 \mathrm{~km}$ above ground level (a.g.l.). The chopper blocking, together with the electronic gating of the photomultiplier tubes (PMTs), helps to reduce the signal-induced noise (SIN) generated by the strong backscatter from low altitudes. The system receiver consists of six photon-counting channels: two high-intensity Rayleigh backscatter channels $(355 \mathrm{H}$ and $308 \mathrm{H})$, two low-intensity Rayleigh backscatter channels (355L and 308L), and two nitrogen Raman backscatter channels (387M and 332M). Up to April 2019, the signals were digitized with Tennelec- 
Nucleus multichannel scaler (MCS) boards with a resolution of $300 \mathrm{~m}$. Since the last system upgrade, a Licel transient recorder with photon-counting and analog detection capabilities has been used. The new acquisition system has a vertical resolution of $15 \mathrm{~m}$.

\subsection{NOAA Mauna Loa Stratospheric Aerosol Lidar}

The NOAA Stratospheric Aerosol Lidar is located in the same building as MLSOL and has been operating with its current configuration since May 1994 (Barnes and Hofmann, 2001). The lidar is based on a Spectra Physics GCR$6 \mathrm{Nd}$ :YAG laser $(30 \mathrm{~Hz}, 40 \mathrm{~W}$ at $1064 \mathrm{~nm})$ with frequency doubling and tripling (532 and $355 \mathrm{~nm}$ ), although the $355 \mathrm{~nm}$ has not been used routinely. A $61 \mathrm{~cm}$ telescope is dedicated to $532 \mathrm{~nm}$ measurements, a $61 \mathrm{~cm}$ telescope is dedicated to $1064 \mathrm{~nm}$, and a $74 \mathrm{~cm}$ telescope is dedicated to Raman nitrogen $(607 \mathrm{~nm})$ and water vapor $(660 \mathrm{~nm})$. PMTs are used in the photon-counting mode for all channels. The system uses a PC 80486 and the data acquisition electronics are MCS II boards made by Tennelec. Measurements are made during the night, usually once a week.

\subsection{The Global Space-based Stratospheric Aerosol Climatology (GloSSAC)}

The GloSSAC (data version 1.1) is a 38-year climatology of stratospheric aerosol properties based on measurements from the SAGE instruments series through August 2005 and a combination of the Optical Spectrograph and InfraRed Imager System (OSIRIS) and CALIOP datasets thereafter (Thomason et al., 2018). The main product reported by this dataset is a series of extinction coefficient profiles at 525 and $1020 \mathrm{~nm}$. The data corresponds to zonally averaged extinction profiles with a latitude grid of $5^{\circ}$ and a vertical grid spacing of $0.5 \mathrm{~km}$ from 5 to $39.5 \mathrm{~km}$.

In the time frame covered by this study, the instruments contributing to the GloSSAC dataset are SAGE II, OSIRIS, and CALIOP. In the case of SAGE II, no major processing is applied, as the aerosol extinction profile at $525 \mathrm{~nm}$ is one of the native data products of the instrument and the vertical grid is also $0.5 \mathrm{~km}$. After the end of the SAGE II mission, in August 2005, and before the start of the CALIOP mission, in August 2006, OSIRIS measurements are reported. After the commissioning of CALIOP, a combination of OSIRIS and CALIOP extinction profiles is provided.

In the case of the CALIOP extinction coefficient calculation, the GloSSAC dataset uses a lidar ratio equal to $53 \mathrm{sr}$ instead of $50 \mathrm{sr}$, as typically used in other stratospheric lidar studies. This difference can be partially attributed to the difference between the original CALIOP wavelength $(532 \mathrm{~nm})$ and the GloSSAC extinction dataset, reported at $525 \mathrm{~nm}$.

\subsection{CALIOP Level 1B}

The CALIOP Level 1B V4.1 (L1) data product provides half orbit (day or night) calibrated and geolocated single-shot lidar profiles, including 532 and $1064 \mathrm{~nm}$ attenuated backscatter and a depolarization ratio at $532 \mathrm{~nm}$. In this study, since it focuses on thin stratospheric plumes, only nighttime profiles of attenuated backscatter at $532 \mathrm{~nm}$ and depolarization are used. Co-located MERRA-2 meteorological profiles including temperature, pressure, and ozone concentration are also provided, which in this case are used as part of the aerosol backscatter coefficient retrieval process (Sect. 4.3).

\subsection{CALIOP Level 3 Stratospheric Aerosol Profile}

The new CALIOP Level 3 (L3) stratospheric aerosol profile product (Kar et al., 2019), released in August 2018, reports monthly mean profiles of aerosol extinction, particulate backscatter, attenuated scattering ratio (SR), and stratospheric aerosol optical depth on a spatial grid of $5^{\circ}$ in latitude, $20^{\circ}$ in longitude, and $900 \mathrm{~m}$ in altitude.

As part of this dataset, two different aerosol products are reported. One is labeled as "background" and the other is labeled "all aerosols". While the first corresponds to profiles retrieved after removing clouds, aerosols, and polar stratospheric clouds (PSCs), the second only screens out clouds and PSCs. For this study, we use the all aerosols data product from dataset version 1.0. Auxiliary atmospheric parameters required for the aerosol extinction coefficient retrieval, including molecular and ozone absorption corrections, are obtained from MERRA-2 (Modern-Era Retrospective analysis for Research and Applications, Version 2) (Gelaro et al., 2017). The lidar ratio assumed for the retrieval is $50 \mathrm{sr}$.

\subsection{SAGE III-ISS}

The SAGE III instrument (Cisewski et al., 2014), launched in February 2017 and carried by the ISS, is a moderateresolution spectrometer covering wavelengths from 290 to $1550 \mathrm{~nm}$. Data collection is performed in three different modes, namely solar occultation, lunar occultation, and limb scatter measurement. The expected science products include vertical profiles of ozone, nitrogen dioxide, and water vapor, along with multiwavelength aerosol extinction.

In this study, zonally averaged extinction profiles at $521 \mathrm{~nm}$ for latitudes between 15 and $25^{\circ} \mathrm{N}$ are used (data version 5.1). Native vertical grid spacing is $0.5 \mathrm{~km}$.

\section{Lidar products and data analysis}

\subsection{Backscatter coefficient retrieval}

Different approaches exist for the calculation of backscatter coefficient profiles out of ground-based lidar measurements, including the Klett inversion technique (Klett, 1985) 
and the scattering ratio approach. Generally speaking, these methods require the knowledge of a reference atmospheric density profile, which is usually derived from co-located radiosonde launches or atmospheric models. In the case of MLSOL, and because this system has Rayleigh and nitrogen Raman channels with high enough signal-to-noise ratio (SNR) to cover the stratospheric aerosol layer, the scattering ratio approach is used, which can be determined based on the ratio of the Rayleigh and Raman signals according to the procedure described elsewhere (Gross et al., 1995; Langenbach et al., 2019).

The main advantage of using the Raman channel as the atmospheric density reference profile for MLSOL is the smaller sensitivity to timing uncertainty. Since before April 2019 the data acquisition of MLSOL had a range resolution of $300 \mathrm{~m}$, the determination of the range zero bin with an accuracy better than $150 \mathrm{~m}$ could not be done with the traditional approach of looking for the first bin with nonzero readings. An error of $150 \mathrm{~m}$ (half a bin in the old MLSOL configuration) in the assumption of the range zero bin can introduce errors of up to $100 \%$ in the calculation of the aerosol backscatter coefficient $\left(\beta_{\mathrm{a}}\right)$ and aerosol optical depth (AOD) in the stratosphere if the Klett method is used. This is mainly due to the error introduced at the time of the so-called range correction. Although alternative methods can be applied to determine sub-bin timing in coarse-resolution systems, this is only possible if access to the configuration under study is possible. Since several changes have been introduced in the systems over the last 20 years, an accurate timing characterization of old setups is not possible. In contrast, the use of the ratio of the Rayleigh and Raman channels cancel the effect of the quadratic range dependence that characterizes lidar signals without the need to know the range zero bin. The only requirement is a well-known relative timing difference between the two channels. Since the Rayleigh and Raman backscatter share the same laser and acquisition timing, this difference is typically very close to zero. As a downside, and due to the limited SNR of the Raman channel, the retrieved profiles are generally noisier than the ones obtained by the Klett algorithm.

The SR retrieval from MLSOL measurements starts with the calculation of the average of the recorded signals for each channel during the length of the measurement period. Typical measurement periods for this lidar correspond to $2 \mathrm{~h}$ measurements after astronomical twilight. After an average profile is obtained for each channel, a correction of the lidar signals for count pile-up (saturation) is applied. This is performed by assuming a non-paralyzable model and dead times that are derived based on the comparison between high- and low-intensity channels available on each system. Following this, the signal background corresponding to moonlight, airglow, and electronic noise is calculated as the mean of the high-altitude tail of the recorded signals, where no contribution of the laser scattering is expected. This background is then subtracted from each signal. Finally, a correction for
Rayleigh extinction is applied to the Rayleigh and Raman channel signals to be used in the calculation of the scattering ratio (Eqs. 1 and 2):

$$
\begin{aligned}
& P_{355}(z)=\frac{N_{355, \mathrm{corr}}(z)}{T_{m, 355}^{2}(z)}, \\
& P_{387}(z)=\frac{N_{387, \mathrm{corr}}(z)}{T_{m, 355}(z) T_{m, 387}(z)},
\end{aligned}
$$

where $P_{\lambda}(z)$ is the Rayleigh-extinction-corrected lidar signal, $N_{\lambda, \text { corr }}(z)$ is the saturation and background-corrected lidar signal, and $T_{m, \lambda}(z)$ is the one-way Rayleigh atmospheric transmission for $\lambda=355$ and $387 \mathrm{~nm}$. The extinction profiles required for this correction are derived from the closest pressure and temperature profiles available from MERRA2. While the effect of the aerosol extinction could also be included in the calculation or corrected using an iterative approach (Friberg et al., 2018), its contribution is small for the cases presented in this study and compared to other uncertainty sources.

The normalization is performed by dividing the signals by the average of the Rayleigh $\left(\overline{P_{355}\left(z_{\text {ref }}\right)}\right)$ and Raman signals $\left(\overline{P_{387}\left(z_{\text {ref }}\right)}\right)$ at a reference altitude range assumed to be free of aerosols ( $z_{\text {ref }}=35-37 \mathrm{~km}$ a.s.l. in this study).

$\mathrm{SR}(z)=\frac{P_{355}(z) \overline{P_{387}\left(z_{\text {ref }}\right)}}{P_{387}(z) \overline{P_{355}\left(z_{\text {ref }}\right)}}$

The scattering ratio is finally calculated as the ratio of the normalized and corrected Rayleigh and Raman signals (Eq. 3).

$\beta_{\mathrm{a}}(z)=(\mathrm{SR}(z)-1) \beta_{\mathrm{m}}(z)$

Once the scattering ratio is calculated, the aerosol backscatter coefficient $\left(\beta_{\mathrm{a}}(z)\right)$ can be retrieved if a molecular backscatter profile $\left(\beta_{\mathrm{m}}(z)\right)$ is assumed (Eq. 4). This reference profile can be derived, as in the case of the molecular extinction, from the MERRA-2 dataset. Uncertainty is calculated following the procedures detailed in Russell et al. (1979).

In the case of the NOAA lidar, the Klett inversion approach is followed, and the SR is calculated based on a radiosonde and model-derived atmospheric density reference profile instead of using a Raman channel. The normalization altitude used is nearly always $38-40 \mathrm{~km}$ a.s.l., which has improved the consistency when compared to the earlier archived profiles in the NDACC database.

\subsection{Extinction coefficient, lidar ratio, and AOD}

While the Raman channel of MLSOL allows the independent retrieval of the aerosol extinction coefficient profiles and lidar ratio at $355 \mathrm{~nm}$ based on technique presented in Ansmann et al. (1990), the application of this method for stratospheric retrievals has been limited to relatively thick stratospheric 
plume due to SNR constraints. As in the case of the backscatter coefficient retrieval, the molecular reference profile required for the inversion is obtained from MERRA-2 temperature and pressure profiles. Based on balloon-borne measurements (Jäger and Deshler, 2002), the extinction Ångström exponent relating the Rayleigh and Raman wavelengths is assumed to be -1.6 . Once a stratospheric extinction profile is derived, the lidar ratio of the stratospheric plume under study is calculated as the ratio of the extinction and backscatter profiles. In this work, the Raman technique is applied to measurements conducted on the Nabro plume, and the results are compared to similar previous measurements (Sect. 5).

Unfortunately, because the Raman-based extinction coefficient retrieval approach is not able to provide acceptable results during most of the period under study because of the generally low aerosol load conditions, the extinction coefficient profiles presented in Sects. 4 and 6 are based on the assumption of a constant lidar ratio. Since the satellite-borne datasets provide extinction profiles at either 525 or $532 \mathrm{~nm}$, the MLSOL backscatter measurements are first translated to $532 \mathrm{~nm}$ using the backscatter coefficient color ratio derived from co-located NOAA lidar measurements (Sect. 5.1). Following this, NOAA lidar and MLSOL backscatter profiles are converted to extinction profiles by assuming a lidar ratio of $50 \mathrm{sr}$, as typically referenced in previous studies (Trickl et al., 2013; Khaykin et al., 2017).

Finally, the stratospheric AOD is calculated by integrating the extinction coefficient profiles between 17 and $33 \mathrm{~km}$.

The calculation of the extinction coefficient uncertainty is performed based on a Monte Carlo analysis, adopting a $3 \%$ standard deviation as the uncertainty on the temperature and pressure profiles from MERRA-2.

\section{The JPL Mauna Loa historical record (1999-2019)}

Between 1 January 1999 and 1 November 2019, MLSOL conducted 2732 measurement sessions with an average duration of $2 \mathrm{~h}$. Based on the method presented in the previous section (Sect. 3), scattering ratio profiles at $355 \mathrm{~nm}$ and stratospheric AOD values at $532 \mathrm{~nm}$ were retrieved and averaged to provide a monthly mean time series (Fig. 1). The number of profiles included in the monthly mean calculation change over time depending on the number of available measurements, with a minimum of 1 , a maximum of 41 , and a mean of 11. Due to technical issues, measurements conducted between the start of the operations in 1994 and the end of 1998 are not included in the discussion.

\subsection{The first "quiescent" period (1999-2006)}

Several studies focusing on midlatitudes refer to the time period between 1997 and 2003 as a quiescent or background period (Trickl et al., 2013; Sakai et al., 2016; Khaykin et al., 2017). In the case of the midlatitude station located in Tomsk,
Russia, a quiescent period between 1999 and 2006 was reported (Zuev et al., 2017). While all definitions imply some degree of arbitrariness, the separation of the time series in periods based on the intensity of the volcanic activity impact helps to organize the discussion. In the case of the MLSOL data series, corresponding to a tropical station, a similar background period between January 1999 and January 2006 can be defined. Although a few eruptions took place during that time frame, with some occurring at equatorial latitudes, no strong impact in the total stratospheric AOD was observed by MLSOL.

The first two eruptions that occurred during this period, corresponding to the Ulawun and Shiveluch volcanos, did not show a clear impact in the extinction profiles derived from MLSOL. After October 2002, some plumes, presumably corresponding to the Ruang and Reventador eruptions, were observed as covering a relatively short period of time with a small impact on the stratospheric AOD. During the background period defined for the MLSOL station, the lidarderived AOD is $\left(2.9 \times 10^{-3} \pm 0.1 \times 10^{-3}\right)$. The variability reported corresponds to $1 \sigma$.

\subsection{The volcanic active period (2006-2013)}

During the time period comprehended between January 2006 and January 2013, several volcanic eruptions with VEI $\geq 4$ took place in the tropics and Northern Hemisphere. The signatures of most of these eruptions are clearly visible in the scattering ratio profiles presented in Fig. 1. These signatures are characterized by a steep increase in the AOD as the plume reaches the MLSOL station, followed by an AOD decay over a period of several months. The e-folding decay time for the AOD eruption signatures that occurred in this period is between 3 and 5 months, with a peak AOD of $11 \times 10^{-3}$ registered in August 2011 as the result of the Nabro eruption (Sawamura et al., 2012). Between eruptions, the AOD quasi-background level reported by MLSOL is about $\left(5 \times 10^{-3} \pm 0.4 \times 10^{-3}\right)$, almost $70 \%$ higher than during the quiescent period described in the previous section.

Despite the fact that stratospheric aerosols interact with incoming solar radiation and stratospheric chemistry and are subject to evaporation and sedimentation (Kremser et al., 2016), they proved to be a useful quasi-passive trace to investigate stratospheric circulation (Trepte et al., 1993). In particular, the diabatic plume ascent induced by residual BrewerDobson circulation (BDC) has been studied based on several satellite observations (Trepte and Hitchman, 1992; Vernier et al., 2009; Fairlie et al., 2014). While analyzing the vertical evolution of the volcanic plumes shown in Fig. 1, a typical "tape-recorder-like" signature as in the case of water vapor observations (Mote et al., 1996) can be seen. Over the lifetime of the eruption plumes, the bottom and top of the plume elevate at a similar rate. In some cases, as previously reported by Vernier et al. (2011), the space left by the plumes is filled with overshooting tropospheric clean air. 


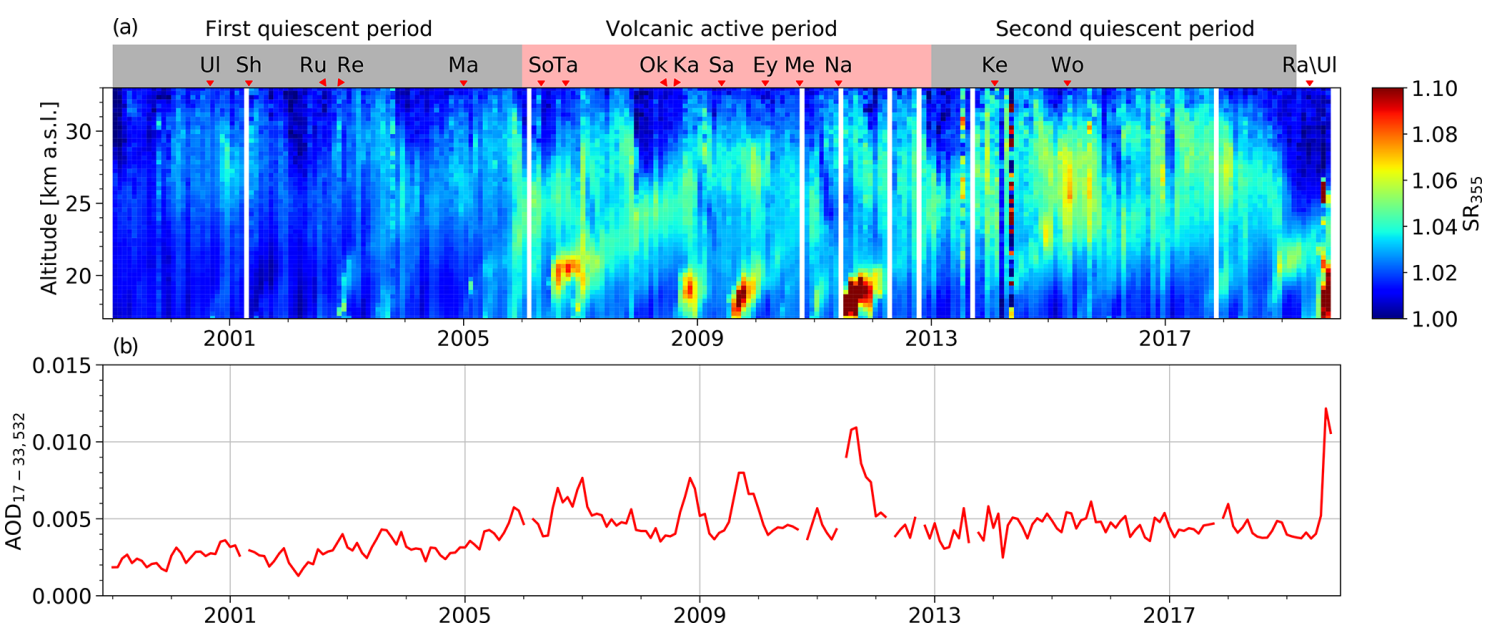

Figure 1. Monthly averaged time series of the stratospheric scattering ratio at $355 \mathrm{~nm}$ retrieved from MLSOL between January 1999 and November 2019 (a). Eruptions with a VEI $\geq 4$ that occurred during this period are indicated at the top of the plot (see Table 1). Three different periods defined based on the impact of the volcanic activity are also shown (see text for details). Monthly averaged AOD retrieved from MLSOL extinction profiles (b).

Table 1. List of eruptions with VEI $\geq 4$ in the tropics and Northern Hemisphere between January 1999 and November 2019. Information regarding the location of the erupting volcano and the maximum plume altitude (MPA) reported by the Global Volcanism Program is included for reference (https://volcano.si.edu/, last access: 10 May 2020). The Raikoke eruption is included in the list, although the VEI has not been determined yet. NA - not available.

\begin{tabular}{llll}
\hline Volcano & Eruption date & Location & MPA (km) \\
\hline Ulawun (Ul) & Sep 2000 & Papua New Guinea $\left(5.0^{\circ} \mathrm{S}\right)$ & 16 \\
Shiveluch (Sh) & May 2001 & Kamchatka $\left(56.6^{\circ} \mathrm{N}\right)$ & $\mathrm{NA}$ \\
Ruang (Ru) & Sep 2002 & Indonesia $\left(2.3^{\circ} \mathrm{N}\right)$ & 22 \\
Reventador (Re) & Nov 2002 & Ecuador $\left(0.0^{\circ} \mathrm{N}\right)$ & 17 \\
Manam (Ma) & Jan 2005 & Papua New Guinea $\left(4.1^{\circ} \mathrm{S}\right)$ & 24 \\
Soufrière Hills (So) & May 2006 & West Indies $\left(16.7^{\circ} \mathrm{N}\right)$ & 20 \\
Tavurvur (Ta) & Oct 2006 & Papua New Guinea $\left(4.2^{\circ} \mathrm{S}\right)$ & 18 \\
Okmok (Ok) & Jul 2008 & Aleutian Islands $\left(53.46^{\circ} \mathrm{N}\right)$ & 15 \\
Kasatochi (Ka) & Aug 2008 & Aleutian Islands $\left(52.17^{\circ} \mathrm{N}\right)$ & 15 \\
Sarychev (Sa) & Jun 2009 & Kuril Islands $\left(48.1^{\circ} \mathrm{N}\right)$ & 17 \\
Eyjafjallajökull (Ey) & Mar 2010 & Iceland $\left(63.6^{\circ} \mathrm{N}\right)$ & 9 \\
Merapi (Me) & Oct 2010 & Indonesia $\left(7.5^{\circ} \mathrm{S}\right)$ & 17 \\
Nabro (Na) & Jun 2011 & Eritrea (13.4 $\left.{ }^{\circ} \mathrm{N}\right)$ & 18 \\
Kelud (Ke) & Feb 2014 & Indonesia $\left(7.9^{\circ} \mathrm{S}\right)$ & 19 \\
Wolf (Wo) & May 2015 & Galápagos Islands $\left(0.0^{\circ} \mathrm{N}\right)$ & 7 \\
Ulawun (Ul) & Jun 2019 & Papua New Guinea $\left(5.0^{\circ} \mathrm{S}\right)$ & $\mathrm{NA}$ \\
Raikoke (Ra) & Jun 2019 & Sea of Okhotsk $\left(48.3^{\circ} \mathrm{N}\right)$ & 17 \\
\hline
\end{tabular}

By analyzing the aerosol plume height evolution over time, a rough estimation of the apparent $\mathrm{BDC}$ ascent rate can be calculated. Figure 2 presents a close-up of the MLSOL measurements of the Sarychev plume and the altitude evolution of the center of the plume as a function of time. For the calculation of the center of the plume, the background extinction calculated based on the mean extinction of the 6 months prior to the eruption is first subtracted from the extinction time series. Since the plume has a vertical profile shape similar to a Gaussian function, a function fit is used to estimate the plume center. The result of this calculation, shown as black crosses in Fig. 2, allow us to estimate the ascent rate between 18 and $19 \mathrm{~km}$ a.s.l. to be about $0.6 \mathrm{~km}$ per month $\left(0.025 \mathrm{~cm} \mathrm{~s}^{-1}\right)$. As the plume rises further, the ascent speed seems to diminish, but a quantitative estimation based on MLSOL data is difficult due to the reduced SNR. This result is on the same order of magnitude as those retrieved based on water vapor and carbon monoxide tape recorder signatures (Minschwaner et al., 2016) and double the ascent rate derived from CALIOP measurements of the Soufrière Hills 


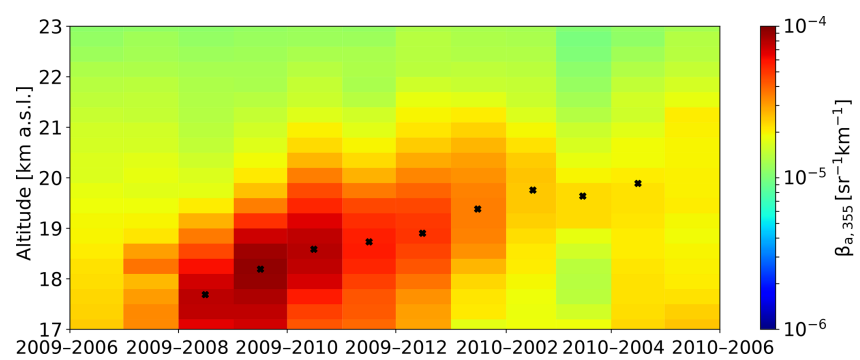

Figure 2. Monthly stratospheric aerosol backscatter corresponding to the Sarychev eruption plume derived from MLSOL. The center of the plume for each month is also shown (crosses, black).

plume (Vernier et al., 2011). For the period between the end of 2009 and beginning of 2010, the ascent rate derived from water vapor records was estimated to be about $0.02 \mathrm{~cm} \mathrm{~s}^{-1}$ at $51 \mathrm{hPa}$ (about $19 \mathrm{~km}$ a.s.l.).

\subsection{The second quiescent period (2013-2019) and Raikoke eruption}

After the decay of the Nabro eruption plume and before the Raikoke eruption, a second relatively quiescent period can be defined based on the aerosol extinction coefficient and AOD records. Although during this period, defined between early 2013 and July 2019, some eruptions with VEI $\geq 4$ occurred, only a slight impact was observed on both the extinction and AOD records. The observed mean AOD for the period is $4.4 \times 10^{-3} \pm 0.7 \times 10^{-4}$, which is $50 \%$ higher than that measured during the first quiescent period and similar to the AOD observed in the period measured between volcanic eruptions in the volcanic active period.

In addition to volcanic eruptions, large wildfires can also contribute to an enhancement of the stratospheric aerosol load (e.g., Khaykin et al., 2018; Zuev et al., 2019). On 12 August 2017, five near-simultaneous extreme pyrocumulonimbus (PyroCb) events took place in British Columbia, Canada. According to recent studies (Peterson et al., 2018), these events injected a mass comparable to a midsized volcanic eruption into the stratosphere. In the case of MLSOL, the smoke plume corresponding to the British Columbia fires was first sensed on 1 September 2017 as a very defined layer of about $1.5 \mathrm{~km}$ thickness at $16 \mathrm{~km}$ a.s.l. In order to relate the origin of this plume to the British Columbia fires and minimize the possibility of a cirrus cloud misclassification, three nighttime CALIOP overpasses around the Mauna Loa Observatory (MLO) area between 29 August and 2 September 2017 were analyzed. For all these overpasses, a thin stratospheric plume at about $15 \mathrm{~km}$ a.s.l. was observed $150 \mathrm{~km}$ north of MLO (Fig. 3). In all cases, the plumes were characterized by a low average particle depolarization ratio $(<0.1)$, which is compatible with smoke particles (Kim et al., 2018). The rapid equatorward transport of the plume seems in agreement with the wind field reported

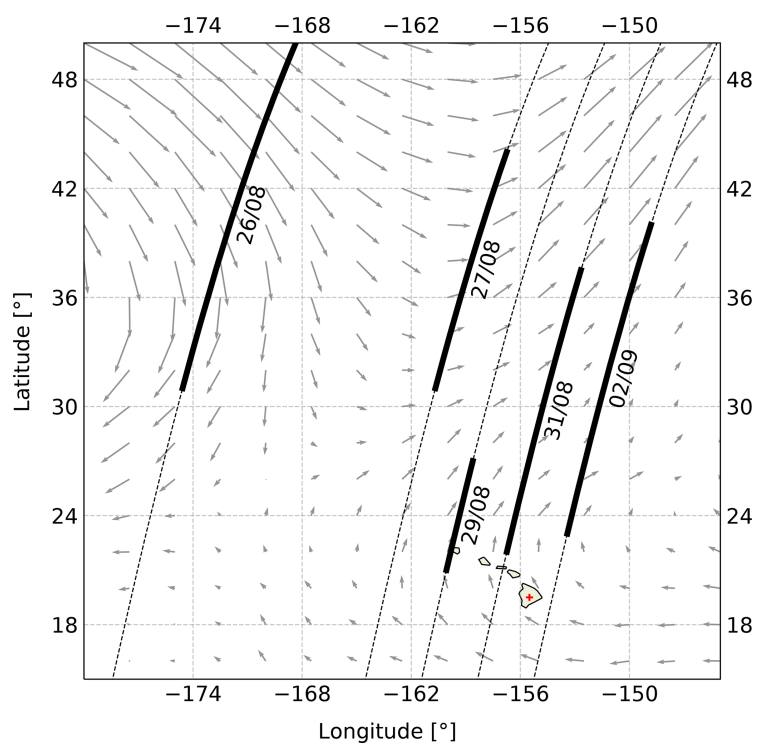

Figure 3. Nighttime CALIOP tracks (dashed black) in the MLO (red cross) area analyzed as part of the PyroCb plume tracking. The spatial extension of the stratospheric aerosol plumes detected during the overpasses are highlighted with thick black lines. MERRA-2 winds at $100 \mathrm{hPa}$ are also shown (black arrows).

by the MERRA-2 reanalysis. Additionally, compatible results can be seen in Fig. 3c presented in Kloss et al. (2019), where transport simulations of the British Columbia fire's smoke by the Chemical Lagrangian Model of the Stratosphere (CLaMS) showed the presence of fire tracers over Hawaii as early as 5 September 2017.

Among these three CALIOP overpasses, the one corresponding to 31 August 2017 provides the closest temporal and spatial data to what is believed to be the first observation of stratospheric smoke injected by the British Columbia fires at MLO. An overview of the CALIOP total attenuated backscatter measurement during that overpass together with the MLSOL measurements for 1 September 2017 is presented in Fig. 4.

Although the plume visible in CALIOP L1 profiles (Fig. 4b) does not seem to reach the MLO latitude, this could be attributed to several reasons, including the lower sensitivity of CALIOP when compared to MLSOL and the spatiotemporal difference between measurements. In order to provide a quantitative assessment of the plume characteristics observed by CALIOP on 31 August 2017 and compare it with the MLSOL observations during 1 September 2017, an aerosol backscatter profile was derived from the CALIOP L1 total attenuated backscatter averaged over the southern end of the plume $\left(21\right.$ to $\left.22^{\circ} \mathrm{N}\right)$. This conversion includes the correction for molecular and ozone extinction and the subtraction of the molecular backscatter component calculated from co-located MERRA-2 temperature and pressure profiles. The intercomparison (Fig. 4a) reveals a strong similarity between the plume elevation and thick- 


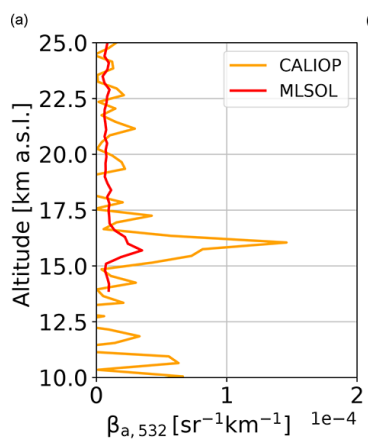

(b) MLSOL CALIOP

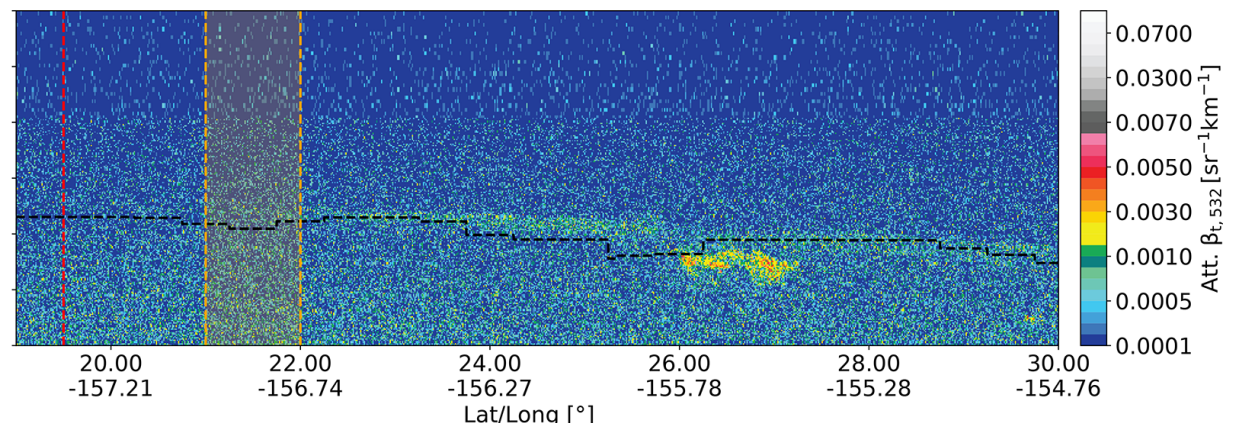

Figure 4. Overview of the CALIOP attenuated backscatter measurements during the 31 August 2019 overpass in the Hawaii area (a). The 1 September 2019 MLSOL aerosol backscatter observations (b, red) are presented together with the aerosol backscatter retrieval from the CALIOP (a, orange) for the southern part of the plume (shaded orange).

ness measured by CALIOP and MLSOL. On the other side, the backscatter coefficient derived from CALIOP measurements peaks at about $1.5 \times 10^{-4} \mathrm{sr}^{-1} \mathrm{~km}^{-1}$, while the MLSOL measurement on 1 September 2017 has a peak value of about $0.2 \times 10^{-4} \mathrm{sr}^{-1} \mathrm{~km}^{-1}$. In both cases, the backscatter is reported at $532 \mathrm{~nm}$. The MLSOL aerosol backscatter was converted to $532 \mathrm{~nm}$ using a color ratio of 0.8 as derived in Sect. 5.1 from co-located MLSOL and NOAA lidar measurements. After the first detection on 1 September 2017, several other plumes were observed by MLSOL over a period of 5 months, with a maximum average plume center altitude of $19.5 \mathrm{~km}$ a.s.l. registered during February 2018 (not shown). While at midlatitudes this PyroCb event produced a large enhancement of the stratospheric AOD (Baars et al., 2019), with peak values over 0.2 , only slight AOD variations were observed at Mauna Loa.

The Raikoke and Ulawun volcanic eruptions, occurring on 22 and 26 June 2019, put an end to the second stratospheric "quiescent" period at Mauna Loa. Although the VEIs of these eruptions are still not quantified, the monthly averaged stratospheric AOD derived from MLSOL for September 2019 was 0.012 , the highest measured value over the last 20 years. In contrast to previous observations of eruption plumes at Mauna Loa, which mainly remained confined to altitudes below $20 \mathrm{~km}$ a.s.l., a thick plume traced back to the Raikoke eruption was observed at altitudes exceeding $26 \mathrm{~km}$ a.s.l. between the end of September and beginning of October 2019 (Fig. 5).

The back trajectory of the Raikoke plume observed at the end of September 2019 by MLSOL was estimated based on CALIOP L1 attenuated backscatter profiles (Fig. 6). The tracking of this plume started with its first detection at Mauna Loa on 24 September 2019 and ended on 17 July 2019 over the Kamchatka Peninsula, Russia. At that point, the track is lost as there are many different plumes in the region. Over a period of slightly over 2 months, the plume ascended $7 \mathrm{~km}$, from 19 to $26 \mathrm{~km}$ a.s.l. The tracking of the plume was conducted mainly through a manual inspection process of

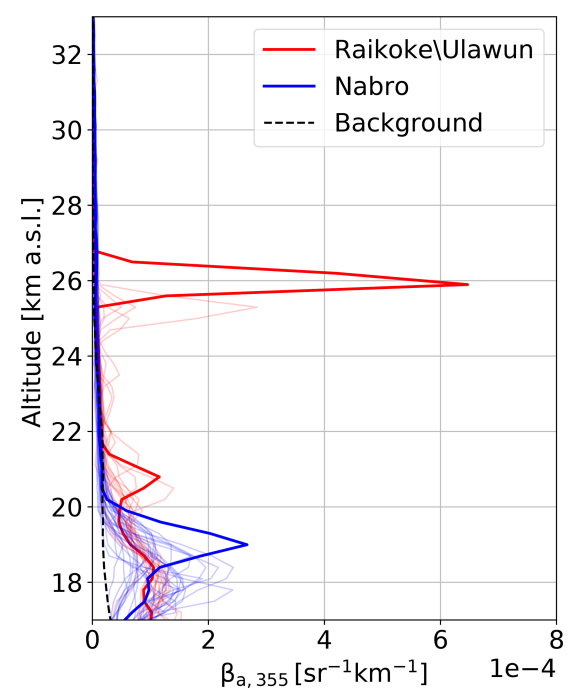

Figure 5. MLSOL-derived daily extinction coefficient profiles for September and October 2019 (solid light red). The extinction coefficient profile for 24 September 2019 is highlighted (solid red). For comparison, the MLSOL-derived daily profiles of the Nabro plume between the end of July 2011 and January 2012 are presented (solid light blue), with the most prominent profile highlighted (solid blue). As background aerosol reference, the monthly averaged extinction profile for June 2019 (black dashed) before the detection of the Raikoke-Ulawun plume is also shown.

CALIOP L1 profiles considering the main stratospheric circulation patterns. This was possible due to the well-defined shape of the plume and its strong backscattering properties when compared to other previously observed volcanic plumes.

While this well-defined and elevated plume is the most prominent feature observed by MLSOL during the period between July and November 2019, an enhancement of the aerosol load between the tropopause and $21 \mathrm{~km}$ a.s.l. was also observed during this period. In order to further investigate whether this plume corresponded to the Raikoke eruption or 


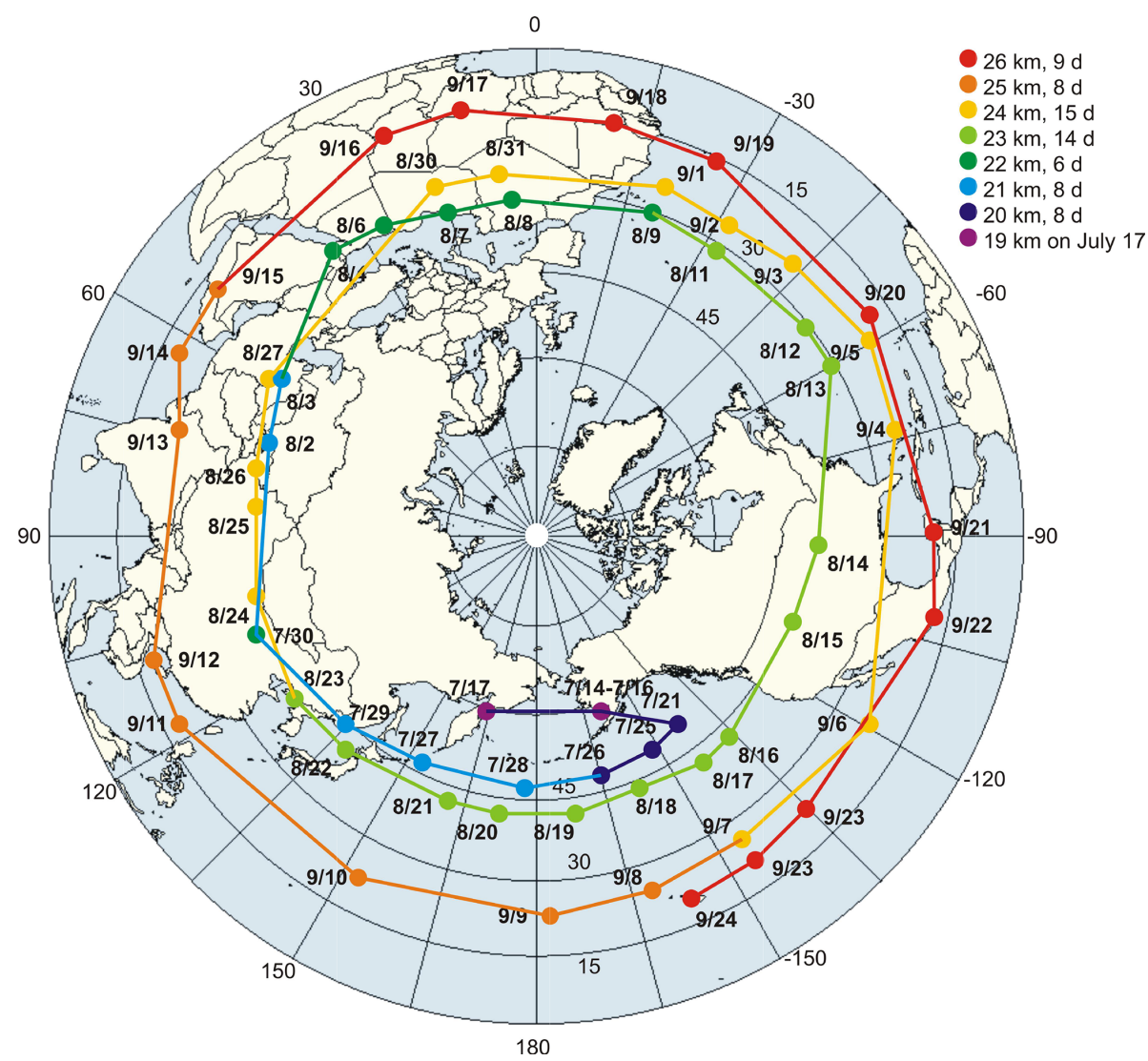

Figure 6. Back trajectory of the Raikoke plume between 24 September and 17 July 2019 derived from CALIOP L1 attenuated backscatter profiles.

the Ulawun eruption, CALIOP L3 longitudinally averaged SR cross sections (latitude vs. altitude) from this period are presented in Fig. 7.

Since no significant stratospheric injection events were registered during the first half of 2019, the SR cross section from June 2019 can be considered the background condition for this analysis (Fig. 7, BKG). Starting in July 2019, an enhancement of the aerosol load is clearly visible between the tropopause and $19 \mathrm{~km}$ a.s.l., with a small gap around $15^{\circ} \mathrm{N}$. This gap corresponds to the division between the plume of the Ulawun (south) and Raikoke (north) eruptions. By August 2019, this gap is closed as both plumes mixed together, making them indistinguishable. Between 30 and $40^{\circ} \mathrm{N}$, a fraction of the Raikoke plume is visible rising above the rest of the plume, confirming the back trajectories presented in Fig. 6. By September 2019, the mixed Ulawun-Raikoke plume reaches $21 \mathrm{~km}$ a.s.l. and increases its SR at low latitudes. The secondary Raikoke plume displaces southward, reaching $20^{\circ} \mathrm{N}$ at an altitude of over $25 \mathrm{~km}$ a.s.l. Finally, the October 2019 cross section starts to show a decay in the SR of the plume, which is compatible with the AOD measurements by MLSOL recorded for that month (Fig. 1).

\section{Lidar-derived optical properties}

Most lidar-derived stratospheric aerosol long-term records consist of backscatter coefficient profiles reported at $532 \mathrm{~nm}$. While some satellite-based datasets, like CALIOP, operate at the same wavelength and also provide aerosol backscatter coefficient as its natural product, other instruments like those of the SAGE series provide extinction profiles at other wavelengths (e.g., $525 \mathrm{~nm}$ ). In the latter case, the comparisons with ground-based lidar datasets require knowledge of the lidar ratio, which is typically derived using Raman lidar measurements. On the other hand, the recently launched Aeolus wind lidar mission (Stoffelen et al., 2005; Flamant et al., 2008) will provide aerosol backscatter and extinction profiles in the lowermost stratosphere at $355 \mathrm{~nm}$. Its validation and intercomparison with other datasets (like CALIOP) will then require a good knowledge of the backscatter and extinction wavelength dependence.

\subsection{The color ratio of the backscatter coefficient}

Based on the co-located backscatter coefficient profiles of MLSOL, NOAA lidar, and CALIOP, the backscatter color ratio (and backscatter Ångström exponent) between 355 and 

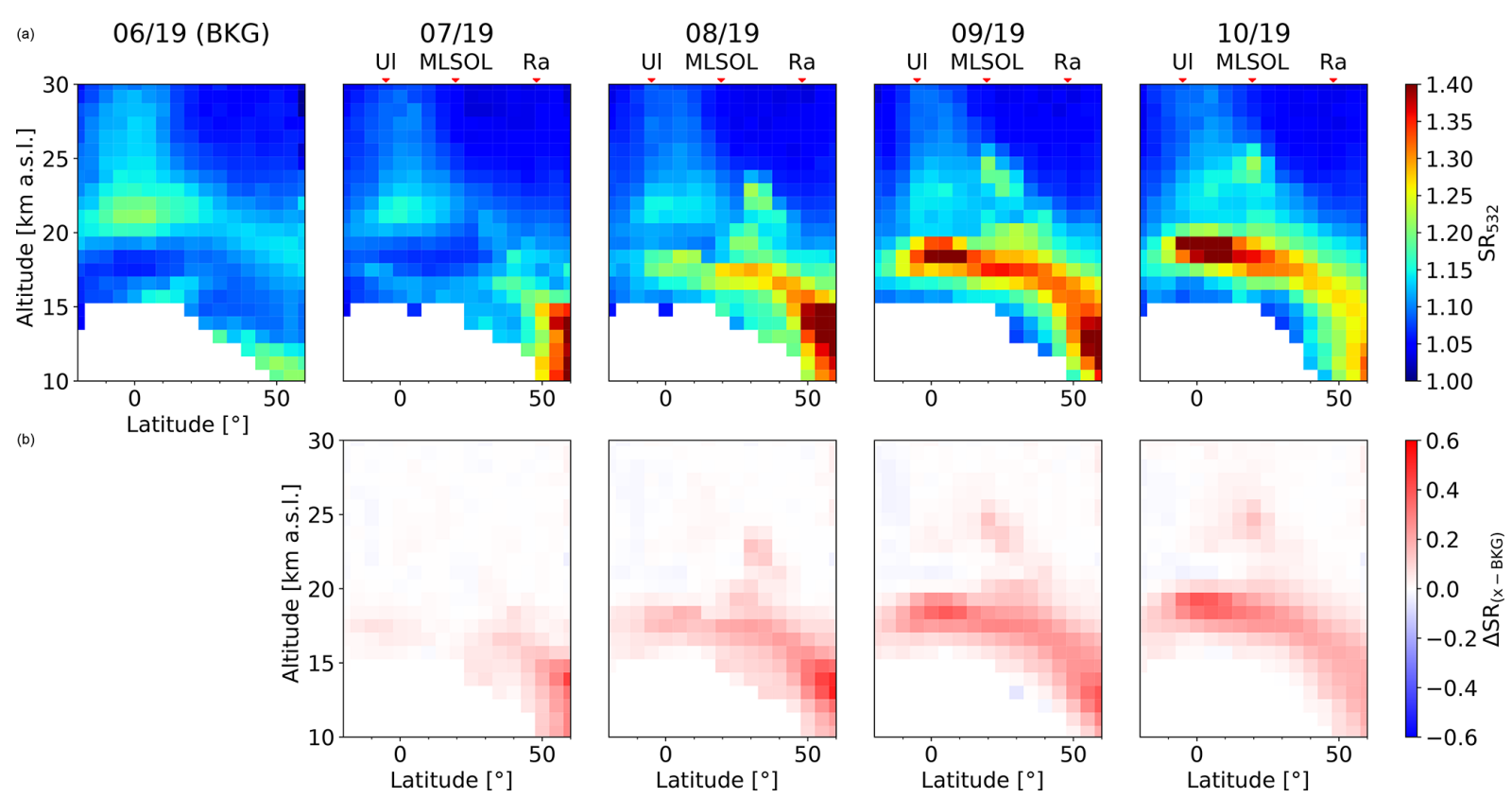

Figure 7. Longitudinally averaged CALIOP L3 SR cross sections (latitude-height) between June and October 2019 (a) are shown together with their difference (b) with respect to the background conditions presented during June 2019.

$532 \mathrm{~nm}$ was calculated as function of altitude and time. Figure 8 presents the temporal average of the color ratio for the volcanic and second quiescent period. In the case of the color ratio derived from CALIOP and MLSOL measurements, the monthly means from both datasets are used. In the case of the color ratio derived from the two ground-based lidars, only same-day measurements are included in the calculation. Because measurements from CALIOP are available only during the volcanic active period and second quiescent period, the measurements from NOAA lidar during the first quiescent period are excluded to simplify the comparison.

Generally speaking, a large color ratio (close to unity) indicates the presence of large particles and is directly associated with a small Ångström exponent (Jäger and Deshler, 2002). This was well documented during the Pinatubo eruption, when Ångström exponent values derived from balloonborne measurements were very close to zero during the first months after the eruption and slowly increased as the plume dissipated (Jäger and Deshler, 2002). In this case, because the eruptions occurred during the volcanic active period were relatively small, no large variations in the color ratio are expected between the two defined periods. In fact, the color ratio profiles derived from the three lidar datasets show similar results above $20 \mathrm{~km}$ a.s.l., with values close to 0.5 and a slight increase as we go from the top of the SAL to about $20 \mathrm{~km}$ a.s.l. One exception is the case of the CALIOP-derived color ratio during the volcanic active period, where results are about $20 \%$ higher than for the rest of the cases. This result is unexpected, as it does not show a good agreement with the other datasets and periods, considering that most of the eruptions only affected the lower part of the SAL. When analyzing the results below $20 \mathrm{~km}$ a.s.l., the color ratio derived from the CALIOP-MLSOL data pair show values that rise up to about 0.7 in the volcanic active period and 0.8 in the quiescent period, while the NOAA lidar-MLSOL pair show a fairly constant color ratio of about 0.5 . This discrepancy is going to be further discussed in the following section (Sect. 6).

Throughout this work, when the backscatter coefficient derived from MLSOL measurements at $355 \mathrm{~nm}$ is required to be converted to $532 \mathrm{~nm}$ (e.g., Sect. 3.2), a smoothed version of the average of the two color ratio profiles derived from the NOAA lidar and MLSOL measurements is used. The values, about 0.5 , are in reasonable agreement with the ones reported by Jäger and Deshler (2002) at the end period affected by the Pinatubo eruption, with a backscatter Ångström exponent equal to -1.4 , corresponding to a color ratio between 532 and $355 \mathrm{~nm}$ of 0.57 .

In the case of high-aerosol events, the color ratio of specific plumes can be derived based on the simultaneous measurements of NOAA lidar and MLSOL. Figure 9 presents two examples, one corresponding to the plume of the Nabro eruption and a second example corresponding to the British Columbia smoke plume. In both cases, the plumes show higher color ratios than the surrounding. In the case of the Nabro example, the average color ratio above the plume is approximately 0.4 , while in the plume the average is about 0.5 . The values observed above the plume are also below the average for other cases (not shown). For the PyroCb plume, the color ratio has a peak value of about 0.8 (correspond- 

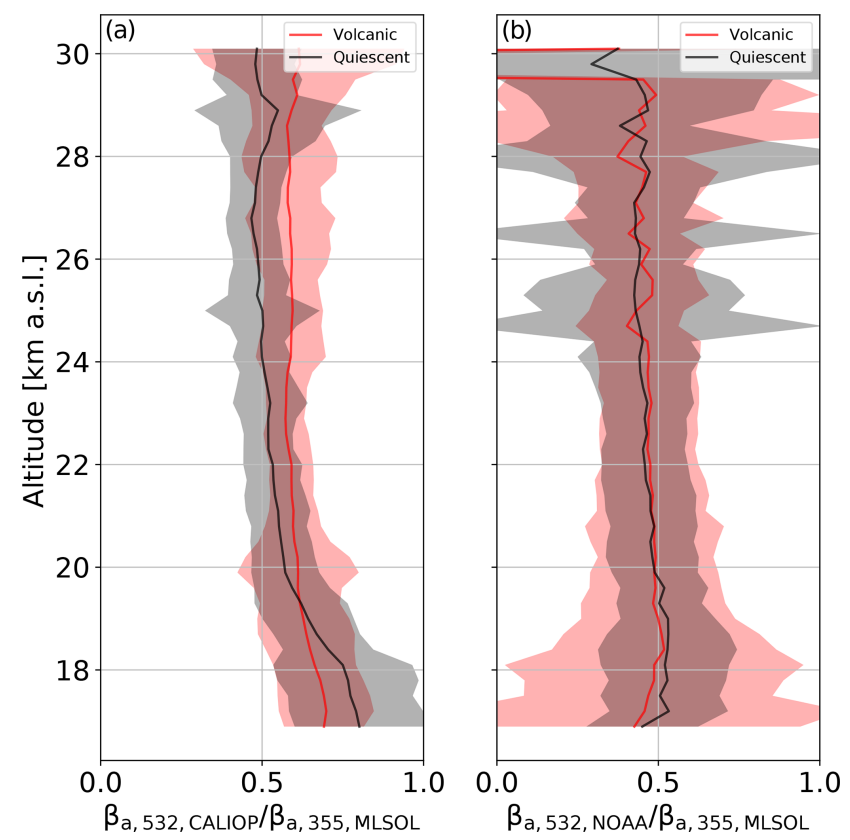

Figure 8. Average color ratio for the volcanic (solid red) and second quiescent (solid black) periods derived from CALIOP and MLSOL measurements (a) and NOAA lidar and MLSOL measurements (b). The $1 \sigma$ variability is indicated by the shaded areas.

ing to an Ångström exponent of -0.6), and values above the plume are in good agreement with the mean corresponding to the second quiescent period.

\subsection{Lidar ratio of stratospheric volcanic aerosols measured after Nabro eruption (2011)}

Due to SNR limitations, direct measurements of stratospheric aerosol extinction profiles by Raman lidars are not common and typically restricted to strong volcanic events like the 1991 Mt. Pinatubo (Ferrare et al., 1992; Ansmann et al., 1993), 2009 Sarychev Peak (Mattis et al., 2010), and 2011 Nabro eruptions (Sawamura et al., 2012). For this reason, most of the long-term stratospheric aerosol lidar studies rely on a lidar ratio derived out of balloon-borne in situ measurements (Jäger et al., 1995). In this study, and thanks to the large receiver, laser power, and elevation of MLSOL, direct aerosol extinction measurements during the Nabro eruption are presented. These measurements allow, in combination with the derived backscatter profiles, the retrieval of the lidar ratio associated with the volcanic plume.

The results presented in Fig. 10, correspond to measurements conducted on 19 July 2011 by MLSOL. A welldefined plume with a peak backscatter coefficient of $0.75 \times$ $10^{-3} \mathrm{sr}^{-1} \mathrm{~km}^{-1}$ was found at $18.7 \mathrm{~km}$. The corresponding extinction was measured to be $4.8 \times 10^{-2} \mathrm{~km}^{-1}$, leading to a lidar ratio of $(64 \pm 12.7) \mathrm{sr}$ at $355 \mathrm{~nm}$ around the center of the plume. The measurement conducted by the Consiglio Nazionale delle Ricerche - Istituto di Metodologie per
l'Analisi Ambientale (CNR-IMAA) of the Nabro plume lidar ratio at $355 \mathrm{~nm}$ was reported to be $(55 \pm 18)$ sr by Sawamura et al. (2012). Considering the large uncertainties associated with these measurements and the spatiotemporal difference in the plume sampling, the results can be considered to be in reasonable agreement.

\section{Intercomparison between MLSOL, NOAA lidar, and satellite-based datasets}

The retrieval of the extinction coefficient out of the CALIOP measurements requires the assumption of a lidar ratio. In the case of the fraction of the GloSSAC dataset where CALIOP is included, this is assumed to be $53 \mathrm{sr}$, while in the CALIOP L3 data product and the profiles derived from MLSOL and NOAA lidar, a lidar ratio of $50 \mathrm{sr}$ is used.

Another point to take into account while comparing the datasets is the differences in their spatial resolution. The GloSSAC dataset provides a zonal average of the extinction profile for a latitude bin of $5^{\circ}$. In contrast, the CALIOP L3 dataset has a longitudinal resolution of $20^{\circ}$. In the case of MLSOL and NOAA lidar and given their ground-based nature and uneven temporal sampling, extinction profiles correspond to a very small atmospheric volume, making them more susceptible to small-scale variability. With regard to the vertical resolution and in order to calculate the corresponding AOD, an interpolation of the GloSSAC and CALIOP L3 datasets needs to be introduced in order to match the MLSOL and NOAA lidar grids.

Finally, it is important to notice that the backscatter retrievals from MLSOL are performed at $355 \mathrm{~nm}$. In order to compare them with the GloSSAC, CALIOP, and NOAA lidar datasets, a conversion following the results from Sect. 5.1 is applied. For the conversion of the GloSSAC extinction dataset from 525 to $532 \mathrm{~nm}$, a constant Ångström exponent of -1.6 is used (Jäger and Deshler, 2002).

The extinction coefficient time series for the five datasets under consideration are presented in Fig. 11. As can be seen here, there is a general qualitative agreement between all the datasets. In the case of GloSSAC and CALIOP, due to the higher amount of more evenly distributed measurements included in the time series calculation, a smoother time series can be observed. In the case of GloSSAC, slight discontinuities in the extinction time series can be noticed around 2006 and 2007, which is likely to be caused by changes in the instruments used for the retrieval as described in Sect. 2.

At the bottom of the stratospheric aerosol layer, between 17 and $23 \mathrm{~km}$ a.s.1., aerosol plumes corresponding to different stratospheric injection events are clearly visible in all datasets. The largest contributions can be easily correlated to volcanic eruptions that occurred in the Northern Hemisphere (Table 1) during the period under study. Due to the strong zonal winds in the lower stratosphere, the MLSOL, NOAA lidar, and CALIOP datasets do not show large dif- 

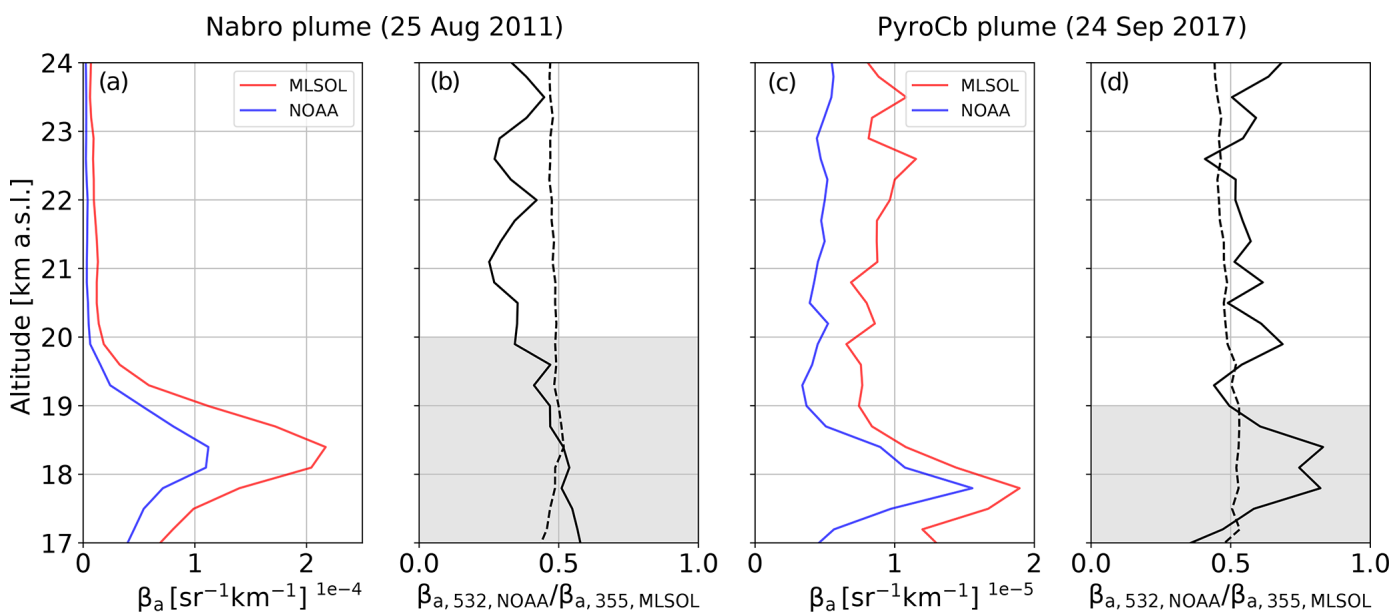

Figure 9. Backscatter derived from MLSOL (red) and NOAA lidar (blue) and corresponding color ratios for the Nabro plume (a, b) and the British Columbia (pyroCb) smoke plume (c, d). In the color ratio plots, the corresponding average color ratio derived for the volcanic active and second quiescent period (see Fig. 8b) is included for reference (dashed black). The altitude interval affected by these two features is highlighted in grey.
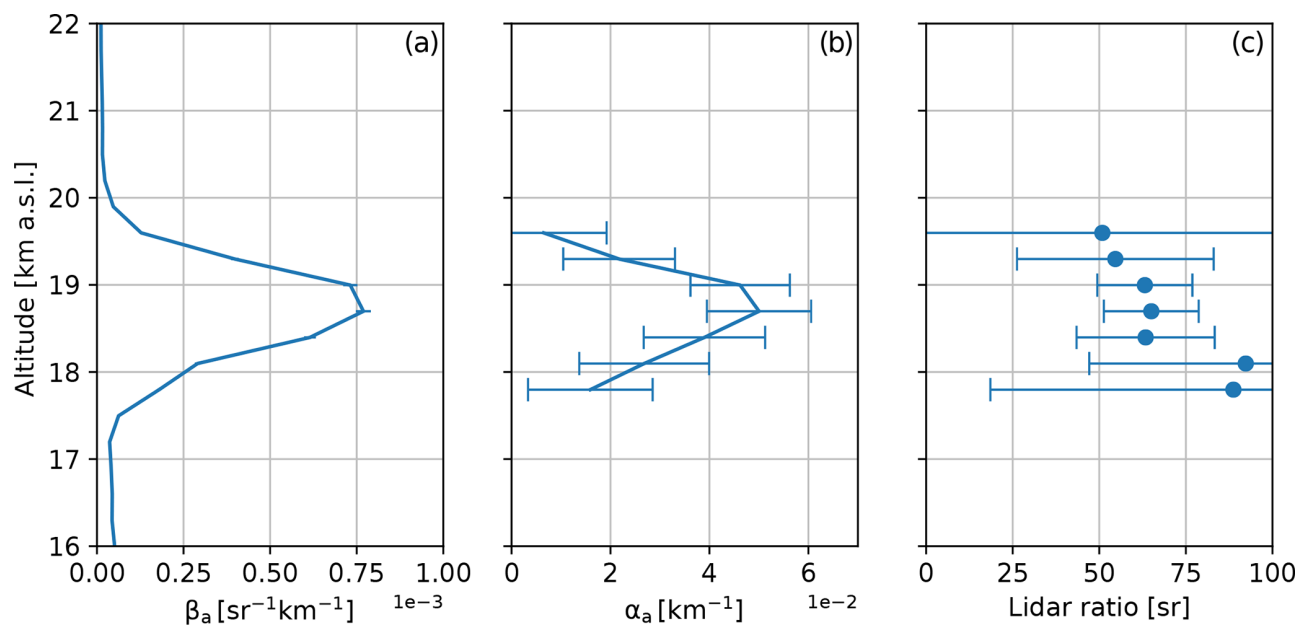

Figure 10. Backscatter (a) and extinction coefficient (b) profiles at $355 \mathrm{~nm}$ measured by MLSOL on 19 July 2011. The derived lidar ratio is also shown (c).

ferences with respect to the zonally averaged GloSSAC and SAGE III-ISS datasets. The top of the layer, on the other hand, shows a modulation on its top altitude that can be associated with the quasi-biannual oscillation (Hommel et al., 2015). In this case, the maximum of the SAL was observed to be at about $32 \mathrm{~km}$ a.s.l., while its minimum can reach as low as $26 \mathrm{~km}$ a.s.l.

In order to provide a better overview of the differences between the datasets under study, the mean relative differences between MLSOL and the other four datasets as a function of altitude and time are presented in Fig. 12. The difference between the two ground-based lidars (Fig. 12d) shows a slight temporally dependent extinction coefficient difference with higher values reported by NOAA lidar during the first quiescent period, and higher values reported by MLSOL dur- ing the volcanic active period and most of the second quiescent period. After the second half of 2018, slightly higher values are reported by NOAA lidar. For the difference between MLSOL and GloSSAC (Fig. 12a), a similar temporally dependent variation is observed, with GloSSAC showing higher extinction values during the first quiescent period and lower values than MLSOL during the volcanic active and second quiescent periods. Below $20 \mathrm{~km}$ a.s.l., the effect of the zonal average on the GloSSAC dataset can be appreciated during volcanic injection events. The zonal average introduces a small shift in the plume temporal shape, which in turn translates into higher values reported by GloSSAC followed by higher values reported by MLSOL. While comparing MLSOL with the CALIOP L3 dataset (Fig. 12b), higher extinction values are generally shown by CALIOP L3. This 

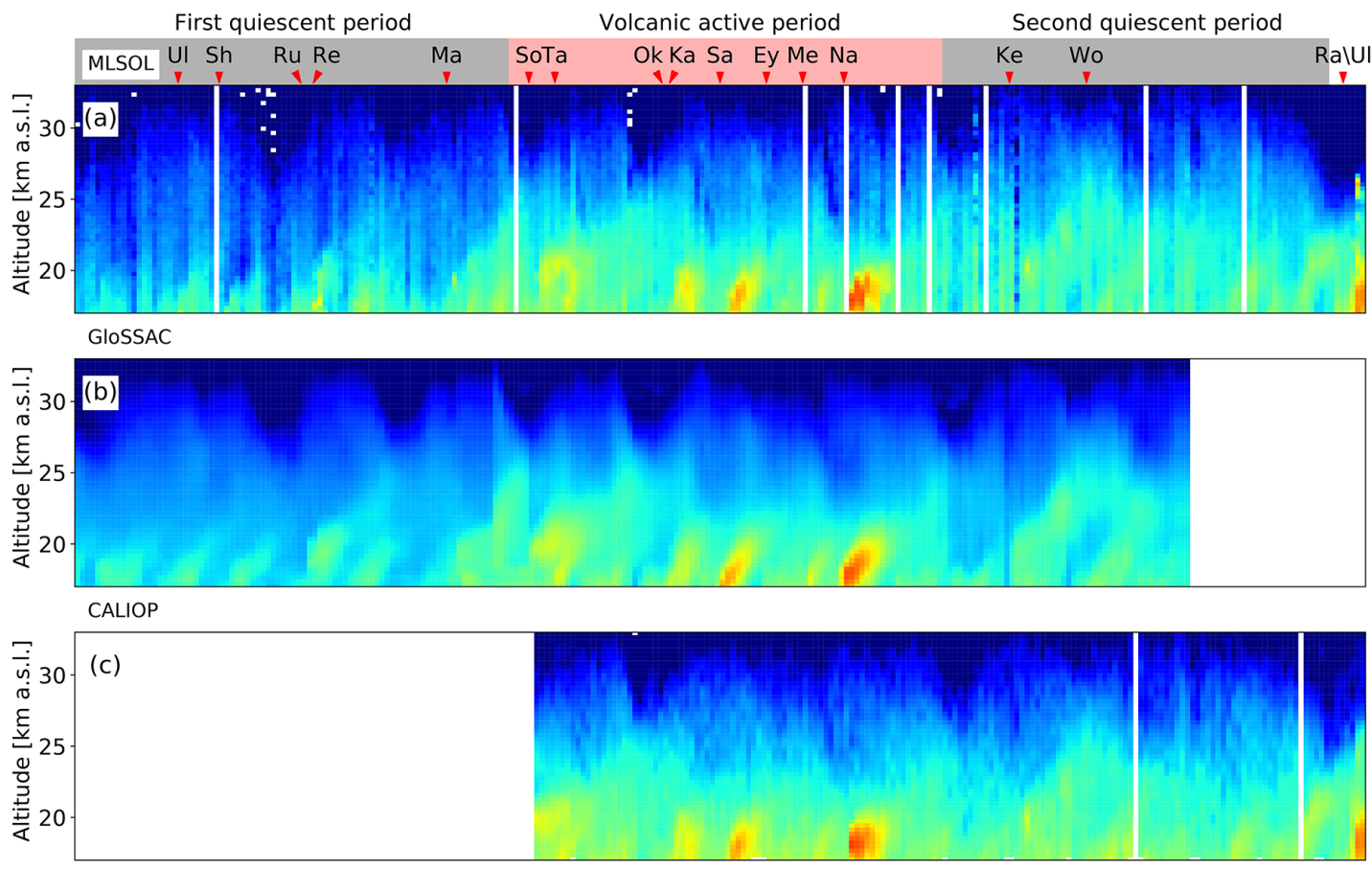

SAGE III-ISS
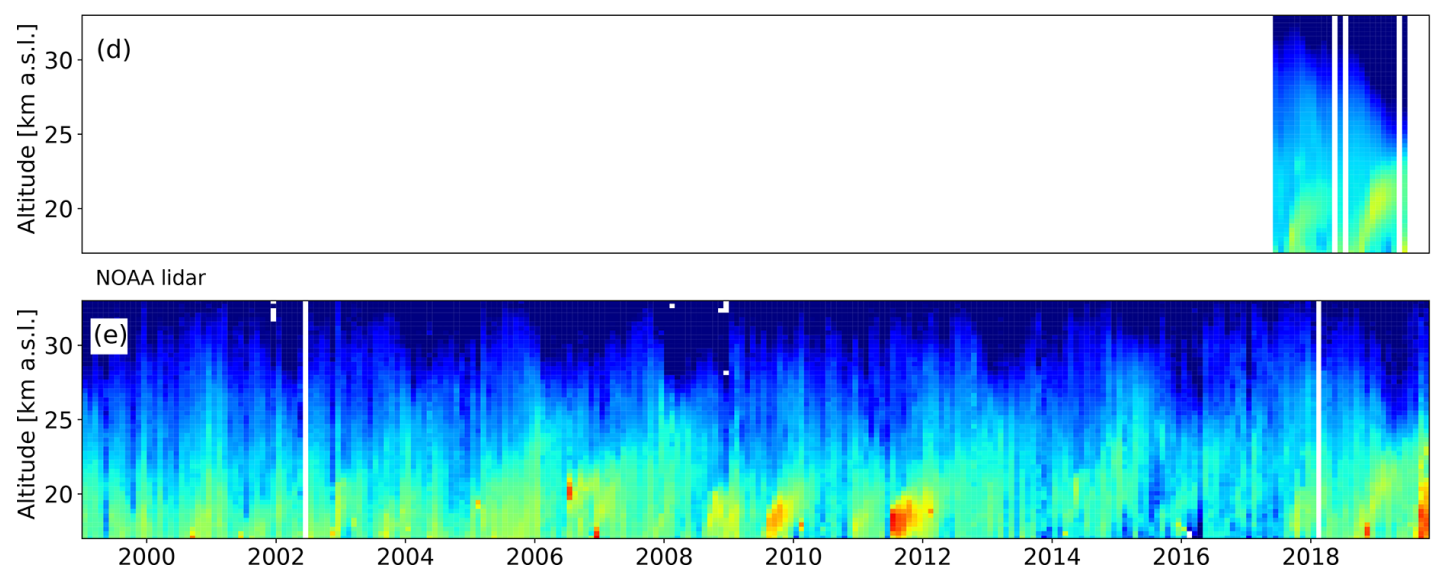

Figure 11. Intercomparison between the monthly mean stratospheric extinction derived from MLSOL, GloSSAC, CALIOP, SAGE III, and NOAA lidar. (a) Extinction coefficient derived from MLSOL measurements between January 1999 and November 2019. (b) Extinction coefficient from the GloSSAC dataset between January 1999 and December 2016. (c) Extinction coefficient from CALIOP L3 dataset between June 2006 and December 2018. (d) Extinction coefficient from SAGE III between June 2017 and April 2019. (e) Extinction coefficient derived from NOAA lidar measurements between January 1999 and April 2019. Eruptions listed in Table 1 are indicated as small red triangles on top of (a) together with the three time periods defined in Sect. 4.

is opposite to what GloSSAC shows for the same time period (for which CALIOP and OSIRIS measurements are used). In order to discard the influence of the zonal averaging in GloSSAC, the CALIOP L3 datasets were zonally averaged. The results (not shown) did not reveal a significant influence of the zonal average that can explain this difference. Finally, the difference with SAGE III-ISS (Fig. 12c) indicates generally higher extinction values by MLSOL, with a small change towards the end of 2018 and beginning of 2019.
Figure 13 provides a more quantitative analysis of the differences between datasets by averaging the results provided in Figs. 11 and 12 over the three periods under study (first quiescent, volcanic active, and second quiescent periods). Although the general agreement between datasets is good, with a maximum relative difference usually around $25 \%$ above $23 \mathrm{~km}$, the differences tend to grow towards the bottom of the vertical profiles. Although in the case of MLSOL and NOAA lidar this difference likely originates from different retrieval approaches, including noise subtraction and normalization, 

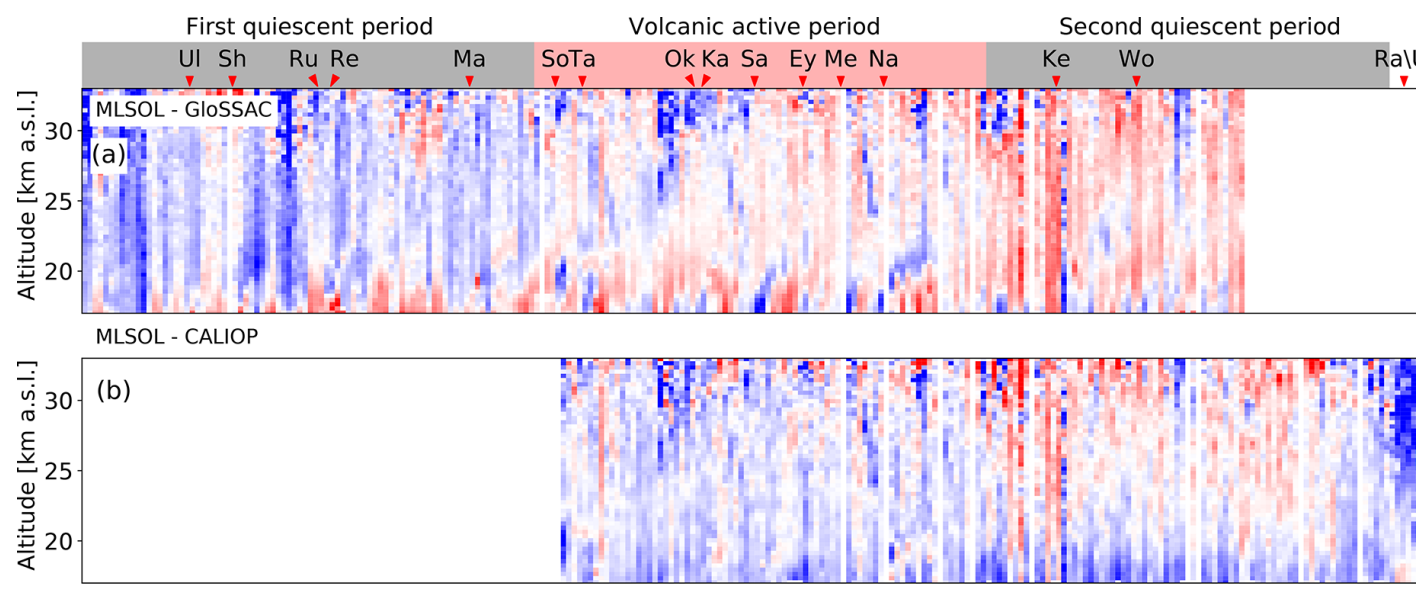

MLSOL - SAGE III
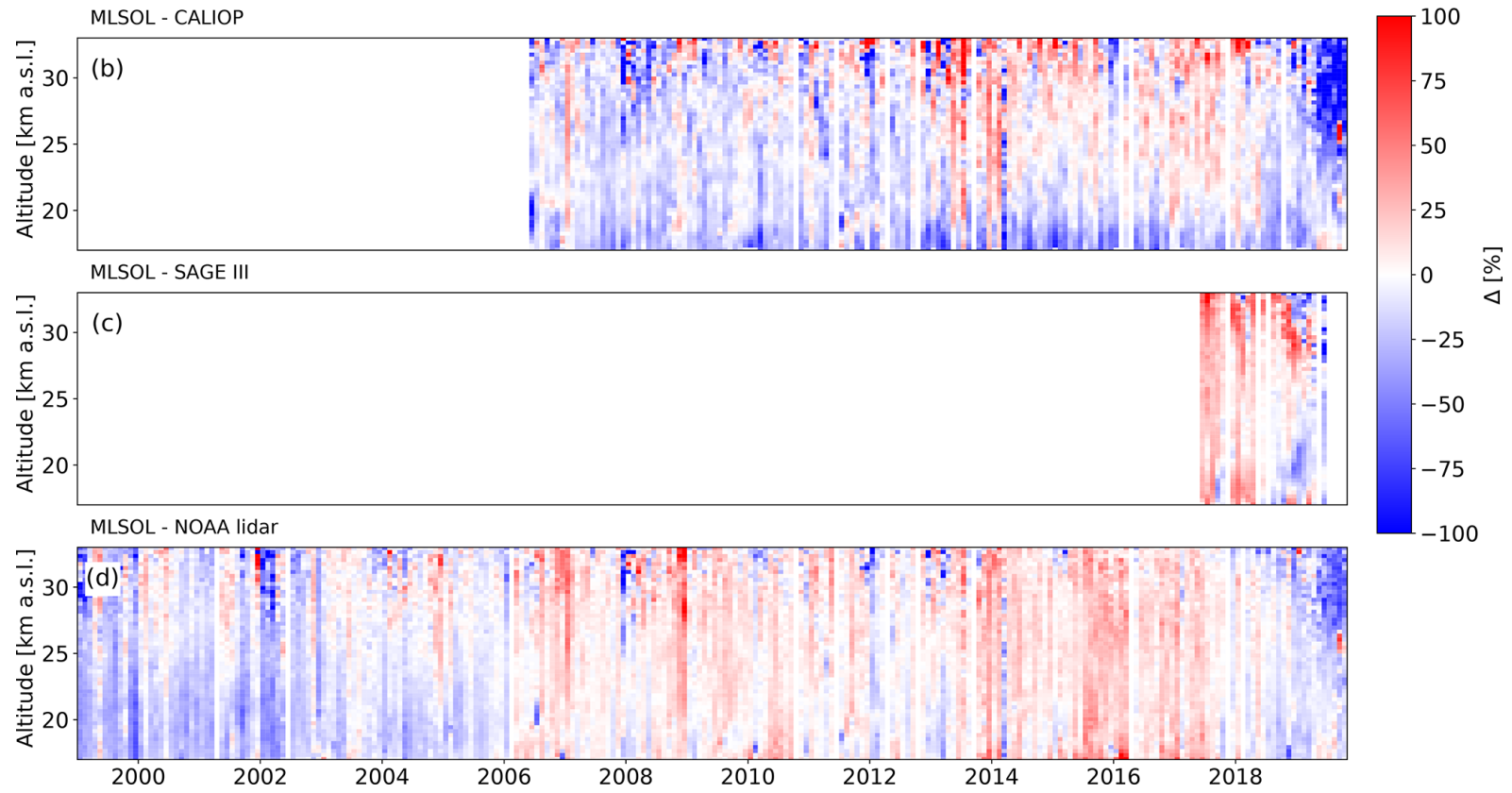

Figure 12. Mean relative difference between MLSOL and GloSSAC (a), CALIOP (b), SAGE III (c), and NOAA lidar (d). The mean relative difference between MLSOL and each other dataset $(X)$ is calculated as (MLSOL $-X) /\left(\frac{\text { MLSOL }+X}{2}\right) \times 100 \%$.

systematic errors caused by misalignment cannot be ruled out. The relative impact of these error sources is currently under investigation. Other differences, as the one shown with the new CALIOP L3 data product, seem to be more systematic, with CALIOP exhibiting consistently higher extinction values when compared with the other two satellite-based datasets and MLSOL. When comparing with NOAA lidar, the CALIOP dataset also tends to show higher extinction values below $23 \mathrm{~km}$, with the exception of the second half of the second quiescent period, where the agreement is good. The agreement of MLSOL with GloSSAC is good, with a relative difference consistently below $20 \%$.

As a final metric to evaluate the agreement between datasets, the corresponding stratospheric AOD at $532 \mathrm{~nm}$ is calculated for the period comprehended between January 1999 and November 2019 and presented in Fig. 14. As expected from the differences observed between the extinction datasets, the MLSOL-derived AOD time series show slightly lower values than GloSSAC and NOAA lidar during the first half of the first quiescent period. After 2003, the agreement between MLSOL and GloSSAC becomes very good. When compared with NOAA lidar, MLSOL shows lower AOD values until 2006. After that, the tendency reverts, with NOAA lidar-derived values generally slightly below MLSOL. As expected from the differences presented in Figs. 12 and 13, the CALIOP-derived AOD is the one showing the largest discrepancy with the other datasets, with values consistently larger (between $12 \%$ and $22 \%$ ) than the rest. For the period influenced by the Raikoke plume, and as in the case of MLSOL, the AOD derived from the NOAA lidar also shows the highest value of the time series. For September 2019, the mean AOD derived from MLSOL measurements was 0.012 , while for the NOAA lidar it was 0.016 . This difference likely originate from the difference in the number of measurements performed by both instruments. In the case of MLSOL, 16 measurements were conducted during September 2019, while only 2 were performed by the NOAA lidar. A general metric of the agreement between datasets is presented in Table 2, where the mean relative differences between AOD time series $\left(X_{\text {row,column }}\right)$ are presented. 

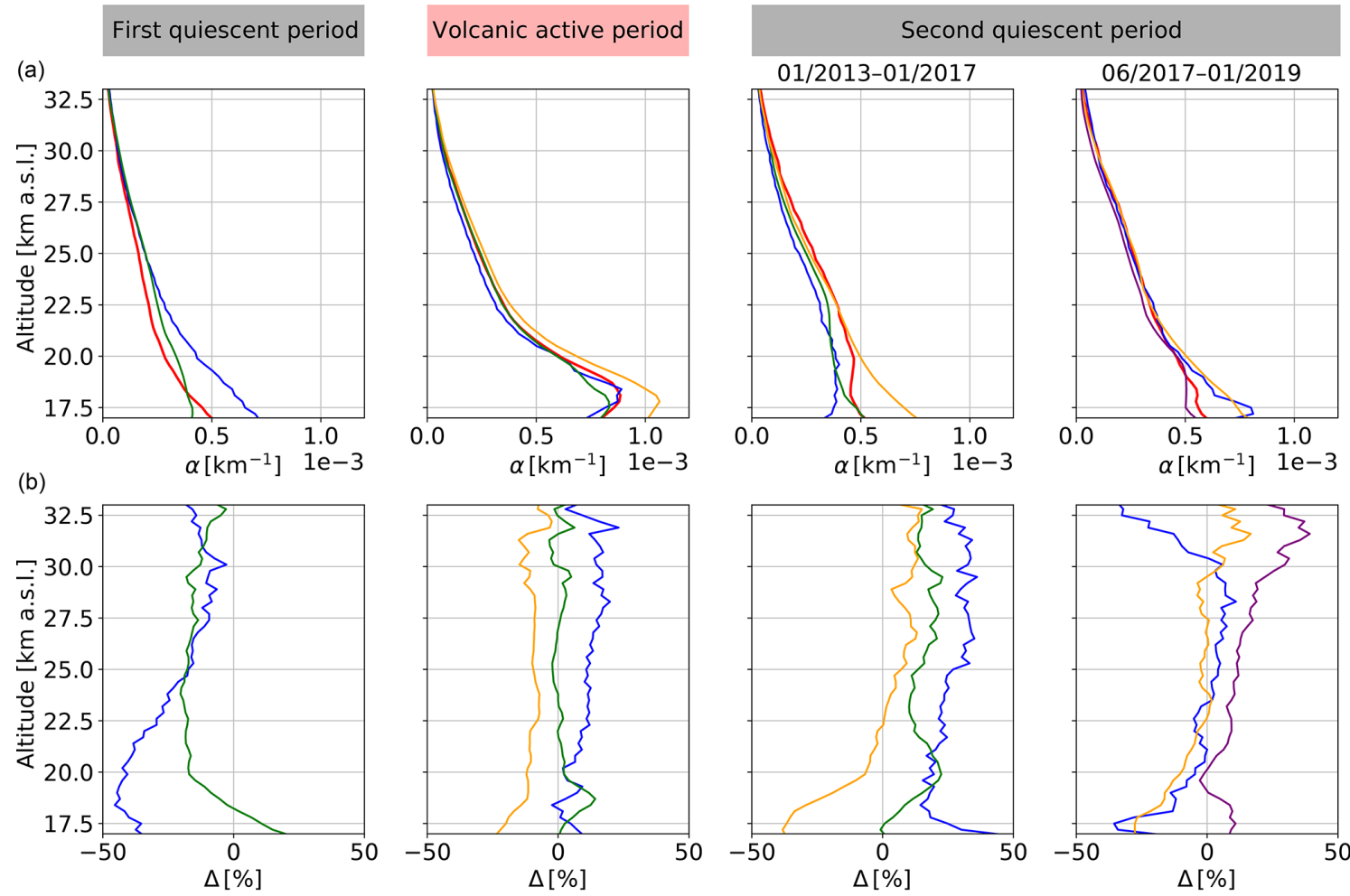

- MLSOL

NOAA lidar

GloSSAC

CALIOP

SAGE III-ISS

Figure 13. Temporally averaged extinction coefficient profiles at $532 \mathrm{~nm}$ for the three pre-defined periods (a) presented together with the mean relative difference between MLSOL and each other available dataset for each period (b). The mean relative difference is calculated as in Fig. 12. In the case of the second quiescent period, the average is split in two sections to take into account the partial temporal coverage of GloSSAC (only the first half) and SAGE III (only the second half).

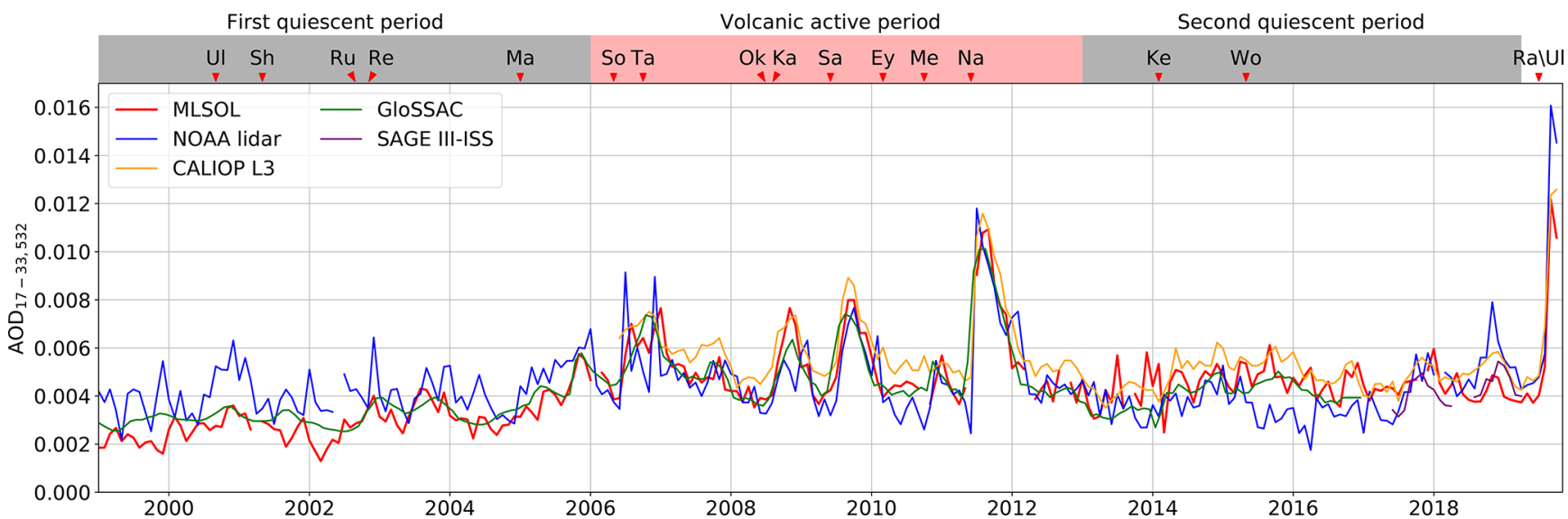

Figure 14. Monthly averaged time series of stratospheric AOD $(17-33 \mathrm{~km})$ derived from MLSOL (red), NOAA lidar (blue), CALIOP (orange), GloSSAC (green), and SAGE III-ISS (purple) extinction datasets.

\section{Summary and conclusions}

Leveraging on the experience of previous studies on lidar stratospheric aerosol retrievals (e.g., Vernier et al., 2009) regarding the selection of a proper normalization altitude, a complete reprocessing of the JPL MLSOL measurements from the beginning of 1999 until the end of November 2019 has been presented in this work. The main difference with respect to the data currently archived at the NDACC repository is given by the use of a consistent normalization altitude (35 
Table 2. Mean relative difference between the AOD time series presented in Fig. 14 for all datasets under intercomparison. The mean relative difference is calculated as $\left(X_{\text {row }}-X_{\text {column }}\right) /\left(\frac{X_{\text {row }}+X_{\text {column }}}{2}\right) \times 100 \%$ to ease comparison with Khaykin et al. (2017) results.

\begin{tabular}{lrrrr}
\hline$\Delta, \%$ & NOAA lidar & CALIOP & GloSSAC & SAGE III-ISS \\
\hline MLSOL & -5.95 & -12.47 & -2.58 & 2.88 \\
NOAA lidar & & -22.73 & 3.13 & 14.8 \\
CALIOP & & & 17.98 & 16.19 \\
\hline
\end{tabular}

to $37 \mathrm{~km}$ ) on the aerosol backscatter and extinction retrieval process over the whole processing period. As an additional outcome for this study, a new version of the JPL MLSOL aerosol product is expected to be uploaded to the NDACC database in the near future.

A first analysis of the extinction time series provided the opportunity to investigate the typical "tape-recorder-like" signature on the different volcanic plumes and the modulation of the SAL top by the Quasi-Biennial Oscillation (QBO). By analyzing the evolution of the Sarychev plume centroid as function of time, an estimate of the ascent rate of the BDC was obtained $\left(0.025 \mathrm{~cm} \mathrm{~s}^{-1}\right)$, as was done in the past with satellite-based water vapor and aerosol observations. The result was shown to be within $20 \%$ when compared with Minschwaner et al. (2016) and double the one reported in Vernier et al. (2011).

Based on this reprocessed long-term dataset and colocated NOAA lidar measurements, an independent retrieval of the stratospheric color ratio (and Ångström exponent) was obtained as a function of altitude and time. The results show a good agreement with previous observations based on balloon-borne measurements (Deshler et al., 2003), which increases the confidence in the values used for several previous studies. In a similar way, thanks to the high-SNR Raman channels available at MLSOL, the lidar ratio at the center of the aged Nabro plume was measured to be $(64 \pm 12.7) \mathrm{sr}$ at $355 \mathrm{~nm}$. Although critical for the derivation of extinction profiles and AOD time series out of typical elastic backscatter lidars, lidar ratio measurements are sparse and typically show high variability and uncertainty. The observed lidar ratio for the presented case was shown to be in relative good agreement (overlapping $1 \sigma$ uncertainties and a $16 \%$ higher mean value for the MLSOL-derived observation) with previously reported measurements from the same event (Sawamura et al., 2012).

Recently released spaceborne long-term datasets of stratospheric aerosol extinction profiles, namely, CALIOP L3, GloSSAC, and SAGE III-ISS, were evaluated by comparing them with MLSOL and NOAA lidar profiles. While a generally good agreement between all datasets (GloSSAC, CALIOP L3 and SAGE III-ISS) and ground-based lidars was observed, the new CALIOP L3 stratospheric data product showed consistently higher values in the lower stratosphere compared to MLSOL and SAGE III-ISS. Further intercomparison between this newly released CALIOP data product and other ground-based datasets is required in order to assess the cause and the extent of this difference.

Finally, the stratospheric AOD at $532 \mathrm{~nm}$ between $17 \mathrm{~km}$ and $33 \mathrm{~km}$ a.s.l. was derived from all datasets under intercomparison. The AOD time series show an increase in the AOD over time while comparing the two defined quiescent periods. This observed increase in the background aerosol levels is in agreement with previously reported observations (Khaykin et al., 2017).

Data availability. Part of the lidar data used for this study is publicly available at the NDACC website (http://www.ndacc.org/, NDACC, 2020). CALIOP data were retrieved from https://opendap.larc.nasa.gov/opendap/CALIPSO (NASA, 2020a). MERRA-2 data were obtained from https://goldsmr5.gesdisc.eosdis.nasa.gov/opendap/ (NASA, 2020b). GloSSAC data were downloaded from https: //opendap.larc.nasa.gov/opendap/GloSSAC/contents.html (NASA, 2020c). SAGE III-ISS data were downloaded from https://opendap. larc.nasa.gov/opendap/SAGE_III_ISS/g3blsp.051/contents.html (NASA, 2020d). For additional data or information, please contact the authors.

Author contributions. FC prepared most of the manuscript and performed the analysis of the JPL lidar (MLSOL) data and statistical comparison with the rest of the instruments. TL is the principal investigator of MLSOL and provided support in the analysis of the MLSOL data. JB is the principal investigator of the NOAA lidar and provided the NOAA lidar data for this study. MB, PW, and DK provided technical support for the collection of the MLSOL data included in this work. All co-authors provided feedback on the manuscript.

Competing interests. The authors declare that they have no conflict of interest.

Acknowledgements. The authors would like to thank the MERRA2, GloSSAC, CALIOP, and SAGE III-ISS teams for providing the data used in this study.

Financial support. The research was carried out at the Jet Propulsion Laboratory, California Institute of Technology, as part of 
the Jet Propulsion Laboratory postdoctoral program, and under a contract with the National Aeronautics and Space Administration (80NM0018D004).

Review statement. This paper was edited by Anja Schmidt and reviewed by Sergey Khaykin, Vladislav Gerasimov, and one anonymous referee.

\section{References}

Ansmann, A., Riebesell, M., and Weitkamp, C.: Measurement of atmospheric aerosol extinction profiles with a Raman lidar, Opt. Lett., 15, 746-748, 1990.

Ansmann, A., Wandinger, U., and Weitkamp, C.: One-year observations of Mount-Pinatubo aerosol with an advanced Raman lidar over Germany at $53.5^{\circ} \mathrm{N}$, Geophys. Res. Lett., 20, 711-714, 1993.

Baars, H., Ansmann, A., Ohneiser, K., Haarig, M., Engelmann, R., Althausen, D., Hanssen, I., Gausa, M., Pietruczuk, A., Szkop, A., Stachlewska, I. S., Wang, D., Reichardt, J., Skupin, A., Mattis, I., Trickl, T., Vogelmann, H., Navas-Guzmán, F., Haefele, A., Acheson, K., Ruth, A. A., Tatarov, B., Müller, D., Hu, Q., Podvin, T., Goloub, P., Veselovskii, I., Pietras, C., Haeffelin, M., Fréville, P., Sicard, M., Comerón, A., Fernández García, A. J., Molero Menéndez, F., Córdoba-Jabonero, C., Guerrero-Rascado, J. L., Alados-Arboledas, L., Bortoli, D., Costa, M. J., Dionisi, D., Liberti, G. L., Wang, X., Sannino, A., Papagiannopoulos, N., Boselli, A., Mona, L., D’Amico, G., Romano, S., Perrone, M. R., Belegante, L., Nicolae, D., Grigorov, I., Gialitaki, A., Amiridis, V., Soupiona, O., Papayannis, A., Mamouri, R.-E., Nisantzi, A., Heese, B., Hofer, J., Schechner, Y. Y., Wandinger, U., and Pappalardo, G.: The unprecedented 2017-2018 stratospheric smoke event: decay phase and aerosol properties observed with the EARLINET, Atmos. Chem. Phys., 19, 1518315198, https://doi.org/10.5194/acp-19-15183-2019, 2019.

Barnes, J. and Hofmann, D.: Variability in the stratospheric background aerosol over Mauna Loa Observatory, Geophys. Res. Lett., 28, 2895-2898, 2001.

Brock, C., Hamill, P., Wilson, J., Jonsson, H., and Chan, K.: Particle formation in the upper tropical troposphere: A source of nuclei for the stratospheric aerosol, Science, 270, 1650-1653, 1995.

Cisewski, M., Zawodny, J., Gasbarre, J., Eckman, R., Topiwala, N., Rodriguez-Alvarez, O., Cheek, D., and Hall, S.: The Stratospheric Aerosol and Gas Experiment (SAGE III) on the International Space Station (ISS) Mission, in: Sensors, Systems, and Next-Generation Satellites XVIII, vol. 9241, p. 924107, International Society for Optics and Photonics, 2014.

Deshler, T., Hervig, M., Hofmann, D., Rosen, J., and Liley, J.: Thirty years of in situ stratospheric aerosol size distribution measurements from Laramie, Wyoming (41N), using balloon-borne instruments, J. Geophys. Res.-Atmos., 108, 4167, https://doi.org/10.1029/2002JD002514, 2003.

Fairlie, T. D., Vernier, J.-P., Natarajan, M., and Bedka, K. M.: Dispersion of the Nabro volcanic plume and its relation to the Asian summer monsoon, Atmos. Chem. Phys., 14, 7045-7057, https://doi.org/10.5194/acp-14-7045-2014, 2014.
Ferrare, R., Melfi, S., Whiteman, D., and Evans, K.: Raman lidar measurements of Pinatubo aerosols over southeastern Kansas during November-December 1991, Geophys. Res. Lett., 19, 1599-1602, 1992.

Fiocco, G. and Grams, G.: Observations of the aerosol layer at $20 \mathrm{~km}$ by optical radar, J. Atmos. Sci., 21, 323-324, 1964.

Flamant, P., Cuesta, J., Denneulin, M.-L., Dabas, A., and Huber, D.: ADM-Aeolus retrieval algorithms for aerosol and cloud products, Tellus A: Dynamic Meteorology and Oceanography, 60, 273-286, 2008.

Friberg, J., Martinsson, B. G., Andersson, S. M., and Sandvik, O. S.: Volcanic impact on the climate - the stratospheric aerosol load in the period 2006-2015, Atmos. Chem. Phys., 18, 11149-11169, https://doi.org/10.5194/acp-18-11149-2018, 2018.

Gelaro, R., McCarty, W., SuÃjrez, M. J., Todling, R., Molod, A., Takacs, L., Randles, C. A., Darmenov, A., Bosilovich, M. G., Reichle, R., Wargan, K., Coy, L., Cullather, R., Draper, C., Akella, S., Buchard, V., Conaty, A., da Silva, A. M., Gu, W., Kim, G.K., Koster, R., Lucchesi, R., Merkova, D., Nielsen, J. E., Partyka, G., Pawson, S., Putman, W., Rienecker, M., Schubert, S. D., Sienkiewicz, M., and Zhao, B.: The Modern-Era Retrospective Analysis for Research and Applications, Version 2 (MERRA-2), J. Climate, 30, 5419-5454, https://doi.org/10.1175/JCLI-D-160758.1, 2017.

Gross, M. R., McGee, T. J., Singh, U. N., and Kimvilakani, P.: Measurements of stratospheric aerosols with a combined elasticRaman-backscatter lidar, Appl. Optics, 34, 6915-6924, 1995.

Hitchman, M. H., McKay, M., and Trepte, C. R.: A climatology of stratospheric aerosol, J. Geophys. Res.-Atmos., 99, 2068920700, https://doi.org/10.1029/94JD01525, 1994.

Hofmann, D. J. and Solomon, S.: Ozone destruction through heterogeneous chemistry following the eruption of $\mathrm{El}$ Chichon, J. Geophys. Res.-Atmos., 94, 5029-5041, https://doi.org/10.1029/JD094iD04p05029, 1989.

Hommel, R., Timmreck, C., Giorgetta, M. A., and Graf, H. F.: Quasi-biennial oscillation of the tropical stratospheric aerosol layer, Atmos. Chem. Phys., 15, 5557-5584, https://doi.org/10.5194/acp-15-5557-2015, 2015.

Jäger, H. and Deshler, T.: Lidar backscatter to extinction, mass and area conversions for stratospheric aerosols based on midlatitude balloonborne size distribution measurements, Geophys. Res. Lett., 29, 35-1, 2002.

Jäger, H., Deshler, T., and Hofmann, D. J.: Midlatitude lidar backscatter conversions based on balloonborne aerosol measurements, Geophys. Res. Lett., 22, 1729-1732, 1995.

Junge, C. E. and Manson, J. E.: Stratospheric aerosol studies, J. Geophys. Res., 66, 2163-2182, https://doi.org/10.1029/JZ066i007p02163, 1961.

Kar, J., Lee, K.-P., Vaughan, M. A., Tackett, J. L., Trepte, C. R., Winker, D. M., Lucker, P. L., and Getzewich, B. J.: CALIPSO level 3 stratospheric aerosol profile product: version 1.00 algorithm description and initial assessment, Atmos. Meas. Tech., 12, 6173-6191, https://doi.org/10.5194/amt-12-6173-2019, 2019.

Khaykin, S., Godin-Beekmann, S., Hauchecorne, A., Pelon, J., Ravetta, F., and Keckhut, P.: Stratospheric smoke with unprecedentedly high backscatter observed by lidars above southern France, Geophys. Res. Lett., 45, 1639-1646, 2018.

Khaykin, S. M., Godin-Beekmann, S., Keckhut, P., Hauchecorne, A., Jumelet, J., Vernier, J.-P., Bourassa, A., Degenstein, D. A., 
Rieger, L. A., Bingen, C., Vanhellemont, F., Robert, C., DeLand, M., and Bhartia, P. K.: Variability and evolution of the midlatitude stratospheric aerosol budget from 22 years of ground-based lidar and satellite observations, Atmos. Chem. Phys., 17, 18291845, https://doi.org/10.5194/acp-17-1829-2017, 2017.

Kim, M.-H., Omar, A. H., Tackett, J. L., Vaughan, M. A., Winker, D. M., Trepte, C. R., Hu, Y., Liu, Z., Poole, L. R., Pitts, M. C., Kar, J., and Magill, B. E.: The CALIPSO version 4 automated aerosol classification and lidar ratio selection algorithm, Atmos. Meas. Tech., 11, 6107-6135, https://doi.org/10.5194/amt11-6107-2018, 2018.

Kirgis, G., Leblanc, T., McDermid, I. S., and Walsh, T. D.: Stratospheric ozone interannual variability (1995-2011) as observed by lidar and satellite at Mauna Loa Observatory, HI and Table Mountain Facility, CA, Atmos. Chem. Phys., 13, 5033-5047, https://doi.org/10.5194/acp-13-5033-2013, 2013.

Klett, J. D.: Lidar inversion with variable backscatter/extinction ratios, Appl. Optics, 24, 1638-1643, 1985.

Kloss, C., Berthet, G., Sellitto, P., Ploeger, F., Bucci, S., Khaykin, S., Jégou, F., Taha, G., Thomason, L. W., Barret, B., Le Flochmoen, E., von Hobe, M., Bossolasco, A., Bègue, N., and Legras, B.: Transport of the 2017 Canadian wildfire plume to the tropics via the Asian monsoon circulation, Atmos. Chem. Phys., 19, 13547-13567, https://doi.org/10.5194/acp-19-135472019, 2019.

Kremser, S., Thomason, L. W., von Hobe, M., Hermann, M., Deshler, T., Timmreck, C., Toohey, M., Stenke, A., Schwarz, J. P., Weigel, R., Fueglistaler, S., Prata, F. J., Vernier, J., Schlager, H., Barnes, J. E., Antuña-Marrero, J., Fairlie, D., Palm, M., Mahieu, E., Notholt, J., Rex, M., Bingen, C., Vanhellemont, F., Bourassa, A., Plane, J. M. C., Klocke, D., Carn, S. A., Clarisse, L., Trickl, T., Neely, R., James, A. D., Rieger, L., Wilson, J. C., and Meland, B.: Stratospheric aerosol-Observations, processes, and impact on climate, Rev. Geophys., 54, 278-335, https://doi.org/10.1002/2015RG000511, 2016.

Langenbach, A., Baumgarten, G., Fiedler, J., Lübken, F.-J., von Savigny, C., and Zalach, J.: Year-round stratospheric aerosol backscatter ratios calculated from lidar measurements above northern Norway, Atmos. Meas. Tech., 12, 4065-4076, https://doi.org/10.5194/amt-12-4065-2019, 2019.

Leblanc, T., Tripathi, O. P., McDermid, I. S., Froidevaux, L., Livesey, N., Read, W., and Waters, J.: Simultaneous lidar and EOS MLS measurements, and modeling, of a rare polar ozone filament event over Mauna Loa Observatory, Hawaii, Geophys. Res. Lett., 33, L16801, https://doi.org/10.1029/2006GL026257, 2006.

Mattis, I., Siefert, P., Müller, D., Tesche, M., Hiebsch, A., Kanitz, T., Schmidt, J., Finger, F., Wandinger, U., and Ansmann, A.: Volcanic aerosol layers observed with multiwavelength Raman lidar over central Europe in 2008-2009, J. Geophys. Res.-Atmos., 115, D00L04, https://doi.org/10.1029/2009JD013472, 2010.

McCormick, M. and Veiga, R.: SAGE II measurements of early Pinatubo aerosols, Geophys. Res. Lett., 19, 155-158, 1992.

McDermid, I. S., Walsh, T. D., Deslis, A., and White, M. L.: Optical systems design for a stratospheric lidar system, Appl. Optics, 34, 6201-6210, 1995.

Minschwaner, K., Su, H., and Jiang, J.: The upward branch of the Brewer-Dobson circulation quantified by tropical stratospheric water vapor and carbon monoxide measurements from the Aura
Microwave Limb Sounder, J. Geophys. Res.-Atmos., 121, 27902804, 2016.

Mote, P. W., Rosenlof, K. H., McIntyre, M. E., Carr, E. S., Gille, J. C., Holton, J. R., Kinnersley, J. S., Pumphrey, H. C., Russell III, J. M., and Waters, J. W.: An atmospheric tape recorder: The imprint of tropical tropopause temperatures on stratospheric water vapor, J. Geophys. Res.-Atmos., 101, 3989-4006, 1996.

NASA: CALIOP dataset, available at: https://opendap.larc.nasa. gov/opendap/CALIPSO, last access: 10 May 2020a.

NASA: MERRA-2 dataset, available at: https://goldsmr5.gesdisc. eosdis.nasa.gov/opendap/, last access: 10 May 2020b.

NASA: GloSSAC dataset, available at: https://opendap.larc. nasa.gov/opendap/GloSSAC/contents.html, last access: 10 May 2020c.

NASA: SAGE III-ISS dataset, available at: https://opendap.larc. nasa.gov/opendap/SAGE_III_ISS/g3blsp.051/contents.html, last access: 10 May 2020d.

NDACC: Stratospheric aerosol database, available at: http://www. ndacc.org/, last access: 10 May 2020.

Peterson, D. A., Campbell, J., Hyer, E., Fromm, M., Kablick, G., Cossuth, J., and DeLand, M.: Wildfire-driven thunderstorms cause a volcano-like stratospheric injection of smoke, Clim. Atmos. Sci., 1, 30, https://doi.org/10.1038/s41612-018-0039-3, 2018.

Rasch, P. J., Tilmes, S., Turco, R. P., Robock, A., Oman, L., Chen, C.-C., Stenchikov, G. L., and Garcia, R. R.: An overview of geoengineering of climate using stratospheric sulphate aerosols, Philos. T. Roy. Soc. A, 366, 4007-4037, https://doi.org/10.1098/rsta.2008.0131, 2008.

Rollins, A. W., Thornberry, T. D., Atlas, E., Navarro, M., Schauffler, S., Moore, F., Elkins, J. W., Ray, E., Rosenlof, K., Aquila, V., and Gao, R.: $\mathrm{SO}_{2}$ Observations and Sources in the Western Pacific Tropical Tropopause Region, J. Geophys. Res.-Atmos., 123, 13 549, 2018.

Russell, P. B., Swissler, T. J., and McCormick, M. P.: Methodology for error analysis and simulation of lidar aerosol measurements, Appl. Optics, 18, 3783-3797, 1979.

Sakai, T., Uchino, O., Nagai, T., Liley, B., Morino, I., and Fujimoto, T.: Long-term variation of stratospheric aerosols observed with lidars over Tsukuba, Japan, from 1982 and Lauder, New Zealand, from 1992 to 2015, J. Geophys. Res.-Atmos., 121, 10-283, 2016.

Sawamura, P., Vernier, J. P., Barnes J. E., Berkoff, T. A., Welton E. J., Alados-Arboledas, L., Navas-Guzman, F., Pappalardo , G., Mona, L., Madonna, F., Lange, D., Sicard, M., GodinBeekmann, S., Payen, G., Wang, Z ., Hu, S., Tripathi, S. N., Cordoba-Jabonero, C., and Hoff, R. M.: Stratospheric AOD after the 2011 eruption of Nabro volcano measured by lidars over the Northern Hemisphere, Environ. Rese. Lett., 7, 034013, https://doi.org/10.1088/1748-9326/7/3/034013, 2012.

Solomon, S., Daniel, J. S., Neely, R. R., Vernier, J.-P., Dutton, E. G., and Thomason, L. W.: The persistently variable "background" stratospheric aerosol layer and global climate change, Science, 333, 866-870, 2011.

Stoffelen, A., Pailleux, J., Källén, E., Vaughan, J. M., Isaksen, L., Flamant, P., Wergen, W., Andersson, E., Schyberg, H., Culoma, A., et al.: The atmospheric dynamics mission for global wind field measurement, B. Am. Meteorol. Soc., 86, 73-88, 2005.

Thomason, L. W., Ernest, N., Millán, L., Rieger, L., Bourassa, A., Vernier, J.-P., Manney, G., Luo, B., Arfeuille, F., and 
Peter, T.: A global space-based stratospheric aerosol climatology: 1979-2016, Earth Syst. Sci. Data, 10, 469-492, https://doi.org/10.5194/essd-10-469-2018, 2018.

Thompson, D. W. and Solomon, S.: Understanding recent stratospheric climate change, J. Climate, 22, 1934-1943, https://doi.org/10.1175/2008JCLI2482.1, 2009.

Trepte, C. R. and Hitchman, M. H.: Tropical stratospheric circulation deduced from satellite aerosol data, Nature, 355, 626-628, https://doi.org/10.1038/355626a0, 1992.

Trepte, C. R., Veiga, R. E., and McCormick, M. P.: The poleward dispersal of Mount Pinatubo volcanic aerosol, J. Geophys. Res.Atmos., 98, 18563-18573, 1993.

Trickl, T., Giehl, H., Jäger, H., and Vogelmann, H.: 35 yr of stratospheric aerosol measurements at Garmisch-Partenkirchen: from Fuego to Eyjafjallajökull, and beyond, Atmos. Chem. Phys., 13, 5205-5225, https://doi.org/10.5194/acp-13-5205-2013, 2013.

Vernier, J. P., Pommereau, J. P. , Garnier, A., Pelon, J., Larsen, N., Nielsen, J., Christensen, T., Cairo, F., Thomason, L. W., Leblanc, T., and McDermid, I. S.: Tropical stratospheric aerosol layer from CALIPSO lidar observations, J. Geophys. Res.-Atmos., 114, D4, https://doi.org/10.1029/2009JD011946, 2009.
Vernier, J.-P., Pommereau, J.-P., Thomason, L. W., Pelon, J., Garnier, A., Deshler, T., Jumelet, J., and Nielsen, J. K.: Overshooting of clean tropospheric air in the tropical lower stratosphere as seen by the CALIPSO lidar, Atmos. Chem. Phys., 11, 96839696, https://doi.org/10.5194/acp-11-9683-2011, 2011.

Zuev, V. V., Burlakov, V. D., Nevzorov, A. V., Pravdin, V. L., Savelieva, E. S., and Gerasimov, V. V.: 30-year lidar observations of the stratospheric aerosol layer state over Tomsk (Western Siberia, Russia), Atmos. Chem. Phys., 17, 3067-3081, https://doi.org/10.5194/acp-17-3067-2017, 2017.

Zuev, V. V., Gerasimov, V. V., Nevzorov, A. V., and Savelieva, E. S.: Lidar observations of pyrocumulonimbus smoke plumes in the UTLS over Tomsk (Western Siberia, Russia) from 2000 to 2017, Atmos. Chem. Phys., 19, 3341-3356, https://doi.org/10.5194/acp-19-3341-2019, 2019. 